\title{
Combustion in reactive multilayer Ni/Al nanofoils: Experiments and
}

A.S.Rogachev ${ }^{1,4^{*}}$, S.G.Vadchenko ${ }^{1}$, F.Baras ${ }^{2}$, O.Politano $^{2}$, S.Rouvimov $^{3}$, N.V.Sachkova ${ }^{1}$, M.D.Grapes ${ }^{5}$, T.P.Weihs ${ }^{5}$, A.S.Mukasyan ${ }^{3,4}$

${ }^{1}$ Institute of Structural Macrokinetics and Materials Science Russian Academy of Sciences (ISMAN), Chernogolovka, Russia

${ }^{2}$ Laboratoire Interdisciplinaire Carnot de Bourgogne, UMR 6303 CNRS - Université Bourgogne Franche Comté, Dijon, France

${ }^{3}$ University of Notre Dame, Indiana 46556, United States

${ }^{4}$ National University of Science and Technology MISiS, Moscow, Russia

${ }^{5}$ Johns Hopkins University, Baltimore, United States

* Corresponding author, rogachev@ism.ac.ru

\section{Introduction}

Reactive multilayer nano-foils (RMNFs) are pore-free reactive materials, which consist of alternating layers of different metals, e.g., Ni/Al, Ti/Al, Pt/Al, with the thickness in the range $4-100 \mathrm{~nm}$, and total number of layers up to several thousand [1-10]. After their invention in 1996 [1], RMNFs have found valuable applications, primarily in the joining of heat-sensitive materials [3-6]. In particular, the $\mathrm{Ni} / \mathrm{Al}$ composition remains the focus of numerous experimental and theoretical works. Local heating of the foil initiates a self-sustained propagating wave of exothermic reaction that is typically considered to be a gasless combustion wave, or the so-called "solid flame". The combustion of Ni/Al RMNFs possesses some unique features including: extremely high heating rates $\left(10^{5}-10^{6} \mathrm{~K} / \mathrm{s}\right)$, combustion front propagation velocities of up to 10 $\mathrm{m} / \mathrm{s}$, and an uncharacteristically low onset reaction temperature $(400-500 \mathrm{~K})$ which is well below the melting points of both reactants [7-9]. It was experimentally found that the value of the combustion front propagation velocity strongly depends on the composition of the foil and 
the bilayer thickness [7]. The specifics of RMNF combustion are discussed further in some reviews [2, 8-10].

In spite of the active research, many features of the self-sustained reaction waves in the $\mathrm{Ni} / \mathrm{Al}$ multilayer nanofoils remain puzzling. For example, it was experimentally shown that the combustion wave involves two stages [11,12], but existing interpretations of this fact are diverse. One explanation is based on the assumption that the first stage is formation of $\mathrm{Ni}_{2} \mathrm{Al}_{3}$ followed by the second stage in which $\mathrm{NiAl}$ appears. Numerical model was recently developed to support this hypothesis [13]. However, in situ experimental investigations of the phase transformations by using of time-resolved transmitting electron microscopy [14,15] and diffraction of synchrotron radiation [16-18] show that $\mathrm{B} 2-\mathrm{NiAl}$ is the only phase that appears in the reaction wave. Another explanation is that reactive dissolution of solid Ni into the Al melt leads the first combustion front, followed by precipitation of $\mathrm{NiAl}$ grains from the saturated liquid $\mathrm{Al}(\mathrm{Ni})$ solution [12]. The third hypothesis is that the first front is attributed to formation of the intermetallic phase, while the secondary combustion reaction is postulated to be oxidation, which transforms a portion of the hot intermetallic compound into metal oxide [10]. Clearly, this explanation cannot be applied for combustion in vacuum or inert gas.

The relationship between propagation of the combustion front and the mechanism of exothermic intermixing of $\mathrm{Ni}$ and $\mathrm{Al}$ atoms also raises questions. Two basic mechanisms of the reaction between the nano-layers can be outlined. First is a well-known reaction diffusion model based on an assumption that diffusion of the reactants through a continuous layer of solid product, which is formed on the boundary between the layers, controls the combustion wave propagation. Resent modifications of this model, developed specially for the RMNFs, assume only formation of continuous intermixed layer, without specification of the phase constitution of this layer: it may be liquid or solid solution, or intermetallic compound [7,19-23]. The second mechanism suggests that macrokinetics of the combustion process is limited by the rate of solid Ni dissolution in liquid Al [24]. 
In our previous works, which involved high-resolution TEM studies and molecular

dynamic simulations, we shed light on the mechanisms of dissolution, precipitation, and grain growth $[25,26]$. The molecular dynamics (MD) employed in those studies is a valuable tool for examining mixing and reactions in $\mathrm{Ni} / \mathrm{Al}$ nanofoils, as their typical length scale (a few nanometers) corresponds precisely to the scale accessible in simulations. Concerning the nanolayered Ni-Al system, MD has been used to study some specific aspects of the Ni-Al nanofoils: the possibility of a reaction at a relatively low temperature and the development of intermetallic phases [27], the effects of the as-deposited microstructure on the initiation of the $\mathrm{Ni}-\mathrm{Al}$ reactive multilayer [28], the interdiffusion of $\mathrm{Ni}$ and $\mathrm{Al}$ at interfaces $[29,30]$, the role of pressure on the initiation of the reaction [31], the nucleation and growth of the B2-NiAl phase at interfaces in RMNF [25] and shock-induced alloying reactions in NiAl nanolaminates [32]. In all of these studies, the simulated systems were limited in size to a few nanometers, which was nevertheless adequate for their purpose. Recently, molecular dynamics were used to simulate larger systems of about $1 \mu \mathrm{m}$. High-temperature, self-propagating reactions were investigated in nanolayered $\mathrm{Ni} / \mathrm{Al}$ foils [33], and reaction mechanisms were studied in thermally ignited core/shell Ni/Al wires [34].

In the present work new experimental results on the thermal structure of the combustion wave in the $\mathrm{Ni} / \mathrm{Al} \mathrm{RMNF}$ are reported and are related to the mechanisms of nano-heterogeneous exothermic reactions. We also apply molecular dynamic simulations to reveal intrinsic features of the nucleation and growth of $\mathrm{NiAl}$ grains so as to validate the suggested mechanism of gasless combustion wave propagation.

\section{Materials and methods}

In the experimental studies we used two types of Ni/Al RMNFs. Type I foils were purchased from Indium Corp. with bilayer thicknesses of $50 \mathrm{~nm}$ and overall foil thickness of 60 $\mu \mathrm{m}$. Thinner foils that were used in quenching experiments, type II foils, were fabricated by dc 
magnetron sputtering of Al 1100 (99 wt \% Al, 0.87 wt \% ( $\mathrm{Si}, \mathrm{Fe}), 0.12$ wt \% Cu) and Ni/V (93 wt $\% \mathrm{Ni}, 7 \mathrm{wt} \% \mathrm{~V}$ ) targets with a bilayer period of $90 \mathrm{~nm}$ and an overall thickness of only $8 \mu \mathrm{m}$. $\mathrm{Ni} / \mathrm{V}$ was used in place of pure $\mathrm{Ni}$ because it is nonmagnetic. Note that commercially purchased foils also use Ni/V for the same reason. For the depositions, substrates are mounted on a rotating carousel positioned between the targets, resulting in a multilayer structure. The chemistry and bilayer spacing of the multilayers were controlled by varying the sputtering power and carousel rotation rate. The depositions were performed in a vacuum chamber evacuated below $2 \cdot 10^{-6}$ Torr and then backfilled to $1 \mathrm{mTorr}$ with $\operatorname{Ar}(99.999 \%$ pure).

Two types of experiments were carried out: free-suspended foil combustion (Fig. 1a), and combustion of foil under intense heat losses (Fig. 1b). For the former scheme a small weight (1 g) was attached to the bottom end of the foil strip not only to prevent bending of the foil during combustion, but also to monitor possible change of the sample's length. For the experiments with intense heat losses, the foil strip was tightly clamped between copper and quartz disks (Fig. 1b). The experiments were conducted in vacuum $\sim 10^{-4} \mathrm{~Pa}$, with the foil strips about $3 \mathrm{~cm}$ long and $0.5-1 \mathrm{~cm}$ wide. A high speed color video camera, MIRO M310, with macro- and microlenses was used for recording the combustion process. Frame-by-frame computer analysis provided time dependences of the combustion front position, while the velocity of the front propagation was obtained by differentiating those dependences. Also, the reaction front brightness profile was monitored using a high-frequency photo-diode sensor pointed at the surface of the foil through steel capillaries with an inner diameter of either 0.2 or $0.4 \mathrm{~mm}$. A high speed infrared camera, FLIR system (SC6000, MA, USA), was used to record the dynamic thermal pattern and to measure characteristic temperature points of the combustion front. Reactions were ignited locally at the top of the foils using three different methods: spark from a $14 \mathrm{~V}$ battery, heat from a thin $(\varnothing 200 \mu \mathrm{m})$ heated tungsten wire, and heat from a relatively thick $(\varnothing 1 \mathrm{~mm}) \mathrm{W}$-coil 
The combustion under high heat losses (Fig. 1b) was carried out in order to extinguish the

combustion wave, to suppress all post-combustion processes, to quench intermediate products, and thereby to obtain a "frozen" combustion wave in the foil. This "frozen" combustion process is called a quenched combustion wave. Crystalline products formed in the quenched combustion wave are primary combustion products, while products of combustion of the free-suspended foil (Fig. 1a) will be referred to as the final product. The structure and composition of the primary and final combustion products were studied using field emission scanning electron microscope "Zeiss Ultra Plus" (Germany) and transmitting electron microscope "Titan" (FEI, USA). Specimens for the TEM studies were prepared using a double beam Nanolab system "Helios" 600 (FEI, USA), and the preparation procedure is described in detail elsewhere [26]. XRD analysis was performed using a DRON-3 goniometer.

Molecular dynamics simulations (MDS) were performed to reveal intrinsic mechanisms of reactive atomic intermixing, and nucleation and growth of the product grains. The experimental conditions were modeled using a $\mathrm{Ni}-\mathrm{Al}$ system, which consists of at least one layer of fcc- $\mathrm{Al}$ in between two layers of fcc-Ni, while the interfaces were oriented normal to the [001] direction. Despite the fact that the NiAl nanofoils used in the experiments were deposited with a (111) texture, the (001) orientation was chosen in the MD simulations to simplify the analysis of the MD results. Nevertheless, we confirmed that both the nature and the sequence of elemental mechanisms were not affected by the choice of the interface orientation ((001) or (111)).Time evolution of this simplified geometry was then followed using the LAMMPS software package [35] with an embedded-atom method (EAM) potential for Ni-Al. This potential, developed by Mishin et al., has been constructed by fitting to experimental properties and ab initio data for the B2-NiAl compound, pure $\mathrm{Ni}$, and pure $\mathrm{Al}$ [36]. The potential provides an effective description of the $\mathrm{B} 2-\mathrm{NiAl}$ and the $\mathrm{L} 12-\mathrm{Ni}_{3} \mathrm{Al}$ structures and is commonly used to study the reactivity of nanolayered Ni/Al multilayers [27]. However, we note that this EAM potential does not reproduce the Al-rich equilibrium phases found within the $\mathrm{Ni} / \mathrm{Al}$ binary system, and this may induce a bias in 
the MDS observations by facilitating the formation of the most stable intermetallic compound NiAl. The formation of transient Al-rich compounds may not be captured by these simulations.

For the simulations the equations of motion are integrated with a time step of $0.002 \mathrm{ps,}$ and a Noosé-Hoover chain has been used for thermalization runs and for production runs in the NPT (isothermal isobaric) or NVT (isothermal isochoric) ensembles. The resulting microstructures were analyzed with the Ackland and Jones approach, which allows the local environment for each atom to be obtained [37]. This method is based on the angle distribution of the nearest neighbors of each atom and enables the identification of fcc metals as well as intermetallic phases (i.e. $\mathrm{B} 2-\mathrm{NiAl}$ with bcc stacking and $\mathrm{L} 12-\mathrm{Ni}_{3} \mathrm{Al}$ with fcc stacking).To reproduce experimental conditions as closely as possible, we conducted two types of calculations:

- Isothermal-isobaric (NPT) simulations with small systems size. As mentioned above, the reaction front in nanofoil propagates extremely fast $(\sim 1-10 \mathrm{~m} / \mathrm{s})$ and is characterized by high temperatures. The reaction front traverses a $10 \mathrm{~nm}$ long sample in less than $1 \mathrm{~ns}$ quickly raising its temperature to a high value. Thus, a set of simulations at constant high temperature was carried out in order to reveal mechanisms associated with the nucleation and growth of the product phases.

Coupling of successive thermodynamics ensembles (NPT, NVT and NVE) for samples that are elongated in one direction. This complex procedure was chosen to reproduce as closely as possible the experimental conditions in which local heating initiates the self-propagating exothermic reaction wave. The atomic system was created and relaxed at 600K (NPT ensemble) using the Parrinello-Rahman scheme [38]. Then, one edge of the sample was heated locally to induce the ignition of the reaction. To do so, atoms with coordinates $\mathrm{x}<50 \mathrm{~nm}$ were thermostated at $1200 \mathrm{~K}$ for $0.08 \mathrm{~ns}$ while the remaining atoms evolved without temperature control. After the ignition stage, the dynamics of the front were followed in the NVE (adiabatic) ensemble for tens of nanoseconds. Details of the simulation procedure are given in [33]. 


\section{Results}

\subsection{Combustion behavior}

A set of selected video frames of the combustion of the free-suspended foil is shown in Fig. 2a. Two qualitative observations can be outlined. First, the radiation emitted by the foil (brightness) does not rapidly decrease behind the reaction front. The lack of a sharp decrease implies that heat losses (mainly radiative in vacuum) do not influence the combustion and postcombustion processes on the time-scale shown, or that additional heat is released across a wide (more than $1 \mathrm{~cm}$ ) post-combustion zone. Second, the foil becomes flexible behind the combustion front, curling up around the vertical axis, but it does not elongate in the vertical direction under the load of the weight attached to its bottom end. These observations suggest that the foil is at most only partially liquid. Some solid phase(s) provide a structural skeleton during the whole combustion process.

The time dependence of the instantaneous propagation velocity of the reaction front, starting from the ignition point, (Fig. 3) shows that the combustion wave reaches a steady-state regime quickly after initiation. Regardless of the ignition method, after a time of $0.5-2 \mathrm{~ms}$, the propagating velocity tends to the same steady-state value of $\sim 7.5 \mathrm{~m} / \mathrm{s}(7.40 \pm 0.06 \mathrm{~m} / \mathrm{s}$ for spark, $7.52 \pm 0.08 \mathrm{~m} / \mathrm{s}$ for wire, and $7.56 \pm 0.11 \mathrm{~m} / \mathrm{s}$ for coil ignition at the distance of $15 \mathrm{~mm}$ ).

A collision of two combustion fronts was observed when the reaction was simultaneously spark ignited in two points within a type I foil (Fig. 4). The locus where the two combustion fronts met each other is visible as a thin line (indicated by arrows in Fig. 4) with higher brightness than the surrounding hot products. According to combustion theory, the excess enthalpy stored in the preheating zones of the colliding combustion waves generates the higher brightness [39]. 
The thermal structure of the combustion wave can be characterized by the brightness profiles obtained from the high-frequency video camera and the photo-diode (Figure 5). The highest space resolution was obtained by computer analysis of the video-frames (Fig. 5a). The exposure time of each frame was $20 \mu \mathrm{s}$, and during this time the combustion wave shifted 150 $\mu \mathrm{m}$ in type I foils $(\mathrm{U}=7.5 \mathrm{~m} / \mathrm{s})$ and $60 \mu \mathrm{m}$ in type II foils $(\mathrm{U}=3 \mathrm{~m} / \mathrm{s})$. Thus, the blurring of the image does not exceed these values. The brightness profiles were measured pixel-by-pixel along the direction of the combustion wave propagation. The profile for the type I foil (curve 1) shows some excess brightness behind the combustion front, that implies slightly higher temperatures in this region that has broadness about $0.5 \mathrm{~mm}$. A zone of increased brightness can be observed just behind the expanding combustion wave in the type I foils shown in Fig. 4. Type II foils (curve 2) show slightly different brightness profiles in a free-standing test setup. After a rapid increase at the wave front, the brightness stays approximately constant for the next $0.3 \mathrm{~mm}$ and then slowly increases in the post-combustion zone over approximately $3 \mathrm{~mm}$. Multiple tests show this general behavior. Under the test conditions of intense heat losses (Fig. 1b), though, the postcombustion rise in brightness was completely suppressed for Type II foils as shown by the rapid rise and fall in brightness for curve 3 in Fig. 5a and thin glowing line that marks reaction propagation in Fig. $2 b$.

The high frequency photo-diode sensor (Fig. 5b and 5c) provided better temporal resolution than the video frames because the measuring time was $5 \mu \mathrm{s}$. However, we must take into account the relatively large aperture diameter (see Fig. 1b) that determines the size of the spot on the foil surface that is visible to the sensor. Comparison of the curves 4,5 , and 6 in Figure $5 \mathrm{~b}$ shows that decreasing the aperture diameter results in a sharper profile and a smaller amplitude. The shape of the combustion fronts, presented by expanded curves in Fig. 5c, also depends on the aperture diameter. The profiles measured with a $0.4 \mathrm{~mm}$ diameter aperture 
(curves 4 and 5) are very broad ( 3-4 $\mathrm{mm}$ ) and have inflections approximately in the middle of the front. The significant difference between the front profiles recorded by high speed video and high-frequency photo-diode can be explained in part by diffuse scattering of IR radiation and visible light that penetrate into the aperture from far zones of the foil, or by different spectral sensitivities. The sharpening of the profile with decreasing aperture diameter supports the first explanation. However, we cannot exclude completely the possibility that the photodiode, having maximum sensitivity in the near infrared at $1800 \mathrm{~nm}$, records an expanded low-temperature preheating zone, which is not visible by high-speed color video camera that records intensity of only visible light (red+green+blue). In the case of the video data, any inflections could be caused by phase transformation, such as the appearance of a liquid phase.

Reactions in type II foils propagate at approximately the same velocity in both freestanding and extreme heat loss conditions as shown in Fig. 6. The reaction front propagates in the free standing foil at a rate of $3,04 \pm 0,01 \mathrm{~m} / \mathrm{s}$, while the velocity of the front under extreme heat loss conditions is $2,99 \pm 0,01 \mathrm{~m} / \mathrm{s}$; and only in the vicinity of extinction point does the propagating velocity decrease to $2,76 \pm 0,03 \mathrm{~m} / \mathrm{s}$. Note that the propagation velocities measured for the foils of type II (bilayer thickness $90 \mathrm{~nm}$ ) are lower than the velocities measured for the foils of type I foils that have smaller bilayer thicknesses $(50 \mathrm{~nm})$, as expected [7].

\subsection{Product structure and reaction mechanism.}

The typical microstructures of the type II foils in the as-deposited state, after reacting under extreme heat loss conditions, and after reacting in free standing conditions are shown in Fig. 7.It can be seen that the initial lamellar microstructure completely disappears in the primary product that appears after reacting under extreme heat losses, and it is replaced by randomly distributed isotropic grains. The diameter of these grains is approximately equal to the thickness of two bilayers. The XRD analysis (Fig. 8) reveals that these fine grains are the B2 NiAl phase, 
which corresponds to the overall initial stoichiometry of the foil. The final product appears after reacting in a freestanding state and is characterized by much larger grains of $\mathrm{NiAl}$.

The surface of the foil with the quenched or arrested combustion wave is shown in Fig. 9. A narrow zone $(\sim 3-4 \mu \mathrm{m}$ wide $)$ with a relatively smooth surface exists at the outer perimeter of the front and is indicated by an arrow. The visible boundary between this zone and initial foil is very sharp $(\leq 0.5 \mu \mathrm{m})$, while the surface with an extremely wavy morphology appears behind this zone.

In order to reveal the mechanism of exothermic atomic intermixing within the nanolayers, cross-sections of type II foils that were quenched and cut from the area marked by the rectangle in Fig. 9 were examined using HR TEM. This area ( $25 \mu \mathrm{m}$ in length) included part of the initial foil, the intermediate zone and part of the "wavy" zone, which corresponds to the primary product shown in Fig. 7. The evolution of the microstructure within the reaction zone is presented in Fig. 10 as a function of distance behind the quenched reaction front. The white phase in Fig. 10 represents an aluminum-rich matrix that was likely liquid at the combustion temperature. The primary solid combustion product appears in the form of rounded grains, which cover part of the Ni/Al interface but do not form a continuous solid layer along the $\mathrm{Ni} / \mathrm{Al}$ boundary (see also $[12,25,26]$ ). The local chemical composition was measured within the white Al-rich phase as a function of distance behind the quenched reaction front using EDS in STEM mode (Fig.11).

It is worth noting that the points of analysis in Fig. 11 were selected manually because:(a) the nanoscale layers are not perfectly straight (automatic line profile mode is not applicable), and (b) the point of analysis needed to be located within white (Al-rich) phase between the product grains. Thus, the distance between the points is not uniform. It can be seen that the Ni concentration in this phase reaches a maximum at a distance about $7 \mu \mathrm{m}$ behind the combustion front and it remains approximately constant thereafter. This concentration likely corresponds to the limit of Ni solubility in $\mathrm{Al}$ at the temperature in the extinction area of the combustion wave. 
Electron micro-diffraction analysis showed the presence of diffraction lines consistent with crystalline $\mathrm{Ni}$ in the range of $\mathrm{L}=0$ to $21 \mu \mathrm{m}$, while diffraction lines consistent with NiAl were found for $\mathrm{L}=9$ to $21 \mu \mathrm{m}$. Intermetallic phases with excess of aluminum, $\mathrm{NiAl}_{3}$ and $\mathrm{Ni}_{2} \mathrm{Al}_{3}$ were also revealed and likely precipitated from the Al-based melt on cooling. Finally, traces of $\mathrm{Al}_{3} \mathrm{~V}$ and residual $\mathrm{Al}$ were detected in the products.

The dominant process that is observed at the second stage of the combustion wave is grain growth. The size of the grains increases sharply with increasing characteristic cooling time, and for the freestanding foil the size of the final grains is approximately $2-3 \mu \mathrm{m}$ (Fig. 7). The character of the fracture surface also changes. In the primary products obtained in the quenched samples, the fractures occur along the grain boundaries, while in the final product from freestanding foil combustion, the fractures transversely cross the grains. It indicates that the weak inter-grain binder phase vanished and grains strongly sintered to each other during the post combustion process.

\subsection{Molecular Dynamic Simulation}

The simulation of a reactive wave at the microscopic level requires a sufficiently large system to allow thermal conductive transport to proceed in at least one direction for a sufficiently long time. Thus the system studied here was $\sim 0.5 \mu \mathrm{m}$ long in the $\mathrm{X}$ direction and contained more than 1.5 million atoms. The ratio between $\mathrm{Ni}$ and $\mathrm{Al}$ atoms equals to 4.3. The use of $\mathrm{Ni}$ excess was introduced in order to stabilize the behavior of the small systems used in MDS. In doing so, we realize that the nucleation of intermetallic compounds is favored by the persistence of a solid/liquid interface, even at high temperature. A self-sustaining reaction, initiated locally by increasing the temperature, was observed to propagate along the foil, without any further supply of heat, due to exothermic intermixing of the two metals (Fig. 12).For this geometry, the MDS results yield a front velocity of about $16 \mathrm{~m} / \mathrm{s}$ and a maximum combustion temperature of $1260 \mathrm{~K}$.

In the non-reacted region in the right half of Fig. 12, $\mathrm{Ni}$ and $\mathrm{Al}$ remain solid; a narrow layer of intermixed atoms appears at the interfaces between the pure metals. These premixed 
interfaces are less than 2-3 nm thick and contain a Ni-Al solid solution. The reaction zone (central part) is quite extended. It covers both the region where the intermixing takes place and the region where the new intermetallic compound is formed. The combustion temperature rises due to the heat released by the intermixing of $\mathrm{Ni}$ and $\mathrm{Al}$ atoms. Note that a crystalline product appears in the form of separate grains, similar to that described in the experimental section. In the reacted region in the left section of Fig. 12 both metals are mixed within a liquid solution and its composition depends on the stoichiometry of the initial sample. Qualitatively, the structure of combustion wave obtained from the MDS method is in good agreement with the microstructures of the quenched combustion wave (Fig. 10), although time and space scales differ to some degree.

The question of nucleation and growth of the intermetallic phase in the self-propagating combustion wave is a key point for understanding the reaction mechanism. To handle this problem by means of MDS, the atomic and microstructure evolution inside the stacked layers was simulated at a fixed temperature. A representative temperature was chosen close to the melting point of Al. Starting from two solid layers of $\mathrm{Ni}$ and $\mathrm{Al}$ stacked together(height is $20 \mathrm{~nm}$ and width is $13 \mathrm{~nm}$ ), the system evolved under NPT conditions in three steps. Fig. 13(left column) shows the same section of the sample at different times. The first stage in the evolution corresponds to the wetting of Ni layers by liquid aluminum and rapid diffusion of $\mathrm{Ni}$ atoms into the Al layer over $2 \mathrm{~ns}$. The second stage starts at $3 \mathrm{~ns}$ and is associated with the nucleation of the intermetallic compound. Well-defined patterns clearly reveal the formation of the new crystalline phase. Finally, the growth and coarsening of the NiAl grains occurs over tens of nanoseconds. Displacements of $\mathrm{Ni}$ and $\mathrm{Al}$ atoms (middle and right columns, Fig. 13) reveal the routes of intermixing. When solid NiAl grains have not appeared yet (0.5 - $2 \mathrm{~ns})$, an intensive diffusional flux of Ni atoms into liquid Al layer can be observed. The whole surface of the Ni layers works as a continuous source of the $\mathrm{Ni}$ atoms, which move into the Al-melt by means of liquid-phase diffusion. When the grains of the new crystalline NiAl phase appear (6-20 ns), they cover part of 
the Ni/Al interface and reduce the rate of intermixing. The reduction is attributed to the fact that mobility of atoms inside the $\mathrm{NiAl}$ grains is negligible: all atoms, $\mathrm{Ni}$ or $\mathrm{Al}$, stay essentially in the same positions inside the B2 crystal lattice. However, rapid atomic movement continues in the liquid phase, and some displacements of atoms can be observed along the interface between $\mathrm{NiAl}$ and solid Ni. The most important point to note is that significant movement of $\mathrm{Ni}$ atoms into the melt occurs only through the liquid gaps between the NiAl grains. The NiAl grains continue to grow, but the gaps stay open. Transport of atoms, required for the growth of the NiAl phase, occurs both through liquid gaps between the grains and along the interface between $\mathrm{NiAl}$ and solid Ni (Fig. 13, 20 - 60 ns). The gaps between NiAl grains work as channels for Ni atoms traveling from solid Ni layers into the Al-based liquid layer.

Since the solid-state diffusional flux of $\mathrm{Ni}$ atoms through the NiAl phase is negligible, the observed growth of the intermetallic grains can occur only due to precipitation of $\mathrm{Ni}$ atoms already in the melt. Results of monitoring of the trajectories of several Ni atoms before they form a fresh NiAl layer on the surface of the growing grain are presented in Fig. 14. The results show that none of the $\mathrm{Ni}$ atom comes through the NiAl layer by solid-state diffusion; all of them precipitated from the melt. Thus, the $\mathrm{Ni}$ atoms that arrived in the molten Al layer through the liquid channels between solid grains precipitate on the growing facets of the NiAl grains.

Dynamics of nucleation and primary growth of the NiAl phase on the interface between solid $\mathrm{Ni}$ and liquid $\mathrm{Al}$ are shown in Fig. 15. Note that the Ni layer remains crystallized in the [001] direction despite small fluctuations of atoms along this direction. At $1 \mathrm{~ns}$, both $\mathrm{Ni}$ and $\mathrm{Al}$ atoms in the reference plane are in a disordered phase (amorphous). At 2 ns, clusters of bcc atoms ( $\mathrm{NiAl}$ phase) randomly appeared. These clusters contain $\mathrm{Ni}$ and $\mathrm{Al}$ atoms arranged in a specific order characteristic of $\mathrm{NiAl}$ intermetallic compound. Careful observation of a layer close to the interface reveals that nucleation occurs in less than $3 \mathrm{~ns}$. The typical size of intermetallic nuclei was found to range from $1 \AA$ to $1 \mathrm{~nm}$. Over the next nanoseconds, the nuclei grow radially by capturing neighboring atoms. During the first $20 \mathrm{~ns}$, the fraction of the interface covered by 
NiAl grains reaches $~ 0.8(80 \%)$. However, this value does not increase with further increase of time, while the vertical growth of the grains continues. Thus, the solid NiAl does not form a continuous layer and does not "block" the whole interface; about $20 \%$ of the disordered or liquid phase remains between the solid grains. It is reasonable to assume that the liquid inter-grains layers remain due to different crystal orientations of the intermetallic grains that have nucleated and prevent a coherent joining of the neighboring crystals.

Finally, it is worth noting that the liquid inter-grain layers also persist through the postreaction stage, when the $\mathrm{NiAl}$ formation is relatively complete and the main process is grain growth. The MDS shows that grain coarsening occurs through dissolution of smaller grains into the melt and precipitation of the dissolved atoms at the surface of larger grains. Thus, the liquid inter-crystalline phase plays a key role on all stages, i.e. formation of NiAl grains and their growth and coarsening.

\section{Discussion}

To explore the intrinsic mechanisms associated with the combustion process in Ni/Al RMNF we begin by discussing the experimental and theoretical results obtained in this work, as well as relevant, previously reported data. First, the exothermic self-propagating waves considered here possess multiple key properties that are associated with a steady-state combustion wave. As shown in Fig. 3 and Fig. 6 the propagation velocity, recorded with the temporal resolution of $0.05 \mathrm{~ms}$ or better and space resolution about $100 \mu \mathrm{m}$, has a unique value, which is independent of the ignition method. The front of the combustion wave carries an excess of enthalpy that becomes visible during collision of two waves (Fig. 4). According to quasi-homogeneous combustion theory, the excess of enthalpy appears in solid or liquid reactive media only if the dimensionless parameter Le $=a / \mathrm{D} \gg>1$, where $a$ and $D$ are thermal and mass diffusivity coefficients, respectively [31]. Thus, the effect of excess enthalpy indicates that mass transfer in the combustion wave in $\mathrm{RMNF} \mathrm{Ni} / \mathrm{Al}$ is much slower than heat transfer. 
Second, the combustion wave in this system involves two stages (Fig. 5): very fast combustion processes. In the foils of type I, the first stage produces the maximum temperature in the combustion front, and temperature remains constant or slowly decreases during the second stage. In the foils of type II, a plateau temperature is reached in the first stage and temperature slowly increases during the second stage. This difference may be generated by the larger bilayer thickness for the type II foils: the degree of reaction achieved during the first stage may be smaller, and more reactants may be present during the post-combustion stage in these foils, as compared to the foils of type I. The surface of the type II foils were also likely smoother and more consistent in chemistry (Al outer layer) compared to the type I foils for which an outer braze coating was removed by sanding. These differences in surface roughness and chemistry could alter surface emissivity and hence the data in Fig. 5. Lastly, we note that the first and second stages of the reaction wave were more pronounced when the profiles were measured in air [12], suggesting that surface oxidation of the foils can affect emissivity coefficient and heat evolution in the RMNFs quite noticeably. The vacuum measurements allow for just the formation reactions and eliminate the impact of oxidation on the shape of the temperature profiles. As seen in Fig. 2 for the case of extreme heat losses, the first stage of reaction wave can propagate alone, without any participation from the second stage. The propagating velocity of the first stage is the same as that for the complete two-stage combustion wave (Fig. 6). Analysis of the primary product of combustion clearly shows that it consists of grains of the final NiAl phase (Figs. 8 and 9). During the second stage, the size of the NiAl grains increases approximately 10 to 100 times and the inter-grain binder phase vanishes (Fig. 7).

The key focus of this research study is the mechanism of the first, extremely fast stage of the reaction process. Two different mechanisms can be applied for self-propagating reactions in Ni/Al RMNFs. The first, derived from the reactive diffusion model [39], assumes that a continuous layer of NiAl separates the nanoscale layers of $\mathrm{Ni}$ and $\mathrm{Al}$, and that the reaction occurs 
via diffusion of atoms throughout this continuous product layer as shown in Fig. 16a. An extensive model, developed later, also requires existing of continuous intermediate layer, but allows solid or liquid state of the intermixed phase; a single diffusion coefficient was derived from this model by fitting experimental data [19]. The best correlation between the model and experimental data was obtained when the mass diffusivity was equal to:

$$
D=2.18 \cdot 10^{-6} \cdot e^{-\frac{16478}{T}} \mathrm{~m}^{2} \mathrm{~s}^{-1}
$$

The values of the activation energy $(137 \mathrm{~kJ} / \mathrm{mole})$ and the pre-exponential factor $\left(2.18 \cdot 10^{-6} \mathrm{~m}^{2} / \mathrm{s}\right)$ were derived from the equation (1) and then were used in multiple theoretical combustion models for Ni/Al RMNFs [20-22]. (Later modeling efforts utilized activation energies and preexponential factors that varied with temperature and hence diffusion mechanisms, but here we consider these initial values and when predicting atomic diffusion.) Using the maximum temperature of $1540 \mathrm{~K}$ that was approximated with FLIR thermal vision system for type II foil reactions, $D_{\max }$ is estimated to be $4.91 \cdot 10^{-11} \mathrm{~m}^{2} / \mathrm{s}$. Using the adiabatic combustion temperature of $1958 \mathrm{~K}$ for the $\mathrm{Ni}+\mathrm{Al}$ reaction [19], the diffusion coefficient is $\mathrm{D}_{\mathrm{ad}}=4.83 \cdot 10^{-10} \mathrm{~m}^{2} / \mathrm{s}$. Both of these values are much higher than the interdiffusion coefficients measured independently for diffusion in bulk NiAl. For example, interdiffusion coefficient in B2-NiAl, measured at $1373 \mathrm{~K}$, equals $5 \cdot 10^{-14} \mathrm{~m}^{2} / \mathrm{s}$ for the $\mathrm{Ni}_{50} \mathrm{Al}_{50}$ composition and may increase up to $\sim 5 \cdot 10^{-13} \mathrm{~m}^{2} / \mathrm{s}$ for $\mathrm{Ni}_{46} \mathrm{Al}_{54}$ [40]. The activation energy and pre-exponential factor for the equimolar phase were found to be $300 \mathrm{~kJ} / \mathrm{mole}$ and $2.5 \cdot 10^{-3} \mathrm{~m}^{2} / \mathrm{s}$, respectively [40]. Experimentally measured diffusion coefficients of $\mathrm{Ni}$ and $\mathrm{Al}$ in the equimolar $\mathrm{NiAl}$ phase at $1540 \mathrm{~K}$ equal $2 \cdot 10^{-14} \mathrm{~m}^{2} / \mathrm{sand} 4 \cdot 10^{-14}$ $\mathrm{m}^{2} / \mathrm{s}$, respectively [41]. In addition, the diffusion activation energies are $260 \mathrm{~kJ} / \mathrm{mole}$ for $\mathrm{Al}$, and $360 \mathrm{~kJ} / \mathrm{mole}$ for $\mathrm{Ni}$ atoms. Thus, in order to match experimental data on the combustion velocity in RMNF Ni/Al system, the diffusivities used in the earlier models, that assume a continuous solution of $\mathrm{Ni}-\mathrm{Al}$ (Fig. 16a), are $2-3$ orders of magnitude larger than those experimentally measured for the bulk intermetallic NiAl. 
An alternative reaction mechanism assumes that the rate of reaction is controlled by solid

$\mathrm{Ni}$ dissolving into molten $\mathrm{Al}$ without the formation of a solid product along the interface (Fig. 16b). This mode of mixing actually consists of two steps: the dissolution of Ni into the Al-Ni melt and then its diffusion across the melt. The first step of dissolution is thought to be much faster than the rate controlling diffusion across the $\mathrm{Al}(\mathrm{Ni})$ liquid layer, as suggested by the concentration gradients observed within the experimental and MDS results. The rate of this diffusion can be approximated by $\mathrm{D}_{\mathrm{liq}} \approx 10^{-9} \mathrm{~m}^{2} / \mathrm{s}$, and represents the most rapid diffusional mixing of $\mathrm{Al}$ and $\mathrm{Ni}$. A conclusion about the leading role of liquid state diffusion in combustion of $\mathrm{Ni}+\mathrm{Al}$ was firstly made basing on comparison of effective activation energies for combustion of fine and coarse powder mixtures [42] and later was suggested for laminar systems [24]. Diffusivity of Ni atoms in the Al-Ni melt has been measured for a wide range of concentrations [43 - 45]. The highest values of Ni-atom diffusion coefficients obtained for Al-rich melts are equal to $7.5 \cdot 10^{-9} \mathrm{~m}^{2} / \mathrm{s}$ at $1525 \mathrm{~K}$ and $10^{-8} \mathrm{~m}^{2} / \mathrm{s}$ at $1795 \mathrm{~K}$ [43]. These values decrease by factor of two in the Ni-rich melts.

The above analysis indicates that the effective diffusivities $\left(\sim 10^{-11} \div 10^{-10} \mathrm{~m}^{2} / \mathrm{s}\right)$ that fit the experimental combustion velocity data sit between the values for solid-state diffusion through an intermetallic phase $\left(\sim 10^{-14}-10^{-12} \mathrm{~m}^{2} / \mathrm{s}\right)$ and liquid-state diffusion $\left(\sim 10^{-9}-10^{-8} \mathrm{~m}^{2} / \mathrm{s}\right)$. Based on the results presented in this work we suggest a new mechanism of nano-heterogeneous reaction that explains not only the effective diffusivities but also the morphology of the products (Fig. 16c). After saturation of the Al-melt by Ni-atoms, crystallites of the intermetallic product (NiAl) nucleate at the solid-liquid interface and grow along the surface forming a mosaic layer which consists of solid NiAl grains separated by liquid gaps. Further growth of the NiAl crystals occurs via diffusion of $\mathrm{Ni}$ through the liquid channels (gaps) and precipitation at the intermetallic-melt interface (Fig.13, Fig.14). According to MDS, diffusion of Ni along NiAl/Ni interface supplies the Ni atoms through the liquid gaps (Fig. 13). Solid state diffusion across the $\mathrm{NiAl}$ grains is negligible. The solid $\mathrm{NiAl}$ grains cover about $80 \%$ of the $\mathrm{Ni}$ surface, thus 
intermixing of reactants continue through the remaining 20\% (Fig. 15), which gives intermediate values of effective diffusivity. We term this reaction mechanism mosaic dissolution precipitation. In the foils with equimolar composition $(\mathrm{Ni} / \mathrm{Al}=1)$, the process finishes when practically all $\mathrm{Ni}$ and $\mathrm{Al}$ atoms are included in the $\mathrm{NiAl}$ grains, excepting small amounts of intergrain Al-Ni melt (Fig. 16c; Fig.7) This composite structures constitutes the primary product.

If small grains of the $\mathrm{NiAl}$ intermetallic form during this first stage for reaction, we then ask the question: can heat still be produced during the second stage? The processes observed in the second stage of the combustion wave include rapid grain growth (Fig. 7) and vanishing of the inter-grain phase, both of which can generate heat. The grain boundary or interface energy of the $\mathrm{NiAl}$ grains varies from 1.25 to $1.85 \mathrm{~J} / \mathrm{m}^{2}[46,47]$, and the diameter of the primary $\mathrm{NiAl}$ grains that appear in the first stage is approximately $20 \mathrm{~nm}$. The grains then grow up to $2000 \mathrm{~nm}$ during the second stage (final product), thereby reducing the area of grain boundaries or interfaces. The heat released due to this decrease of the grain boundary area can be estimated as follows:

$$
Q_{S}=\frac{6 M \varepsilon}{\rho}\left(\frac{1}{d_{0}}-\frac{1}{d_{F}}\right)
$$

where $M=0.0857 \mathrm{~kg} / \mathrm{mol}$ is a molecular mass, $\rho=5860 \mathrm{~kg} / \mathrm{m}^{3}$ is the density of $\mathrm{NiAl}, \mathrm{d}_{0}$ is the initial $\mathrm{NiAl}$ average grain diameter and $\mathrm{d}_{\mathrm{F}}$ is the final $\mathrm{NiAl}$ average grain diameter. Using equation (2) we estimate that the heat released due to grain growth falls in the range of 5.5 to 8.1 $\mathrm{kJ} / \mathrm{mol}$. Therefore, the NiAl grain growth process can generate significant heat, although much lower than the heat of the $\mathrm{Ni}+\mathrm{Al}$ chemical reaction $(120 \mathrm{~kJ} / \mathrm{mol})$. This conclusion correlates well with the experimentally measured temperature profiles. The growth of the average NiAl grain size can occur due to the dissolution of small grains and precipitation of the dissolved matter at the surface of large grains according to the Ostwald ripening mechanism. Some heat can also be released by reaction of the residual inter-grain melt with the solid phase, which shifts composition of the grains closer to the stoichiometric 1:1 value.

Finally, let us consider the possible role of solid-state intermixing in these selfpropagating reactions. The experimental and theoretical results of this work support the 
hypothesis that a molten phase plays a critical role in the combustion and structure formation mechanisms. However, the temperature of self-ignition of the Ni/Al RMNFs that has been reported in the literature is about $500 \mathrm{~K}$, much lower than the melting points of $\mathrm{Al}$ and $\mathrm{Ni}$ $[2,8,9,12,48,49]$. These ignition temperatures may be further decreased, for example, by ion beam irradiation [50]. Is it possible that the expanded low-temperature zone observed in some brightness profiles (curves 4 and 5, Fig. 5) was generated by solid-state reactions? The broadness of the preheating zone of the combustion wave can be estimated as $l \approx a / U \sim 0.01 \mathrm{~mm}$, which is much less than the size of the "low-temperature" part of the mentioned curves (we assume $\mathrm{a} \sim 0,75 \mathrm{~cm}^{2} / \mathrm{s}$ for the Ni/Al lamellar composite). The period of time during which the initial material stays in the preheating zone is $t \approx a / U^{2} \sim 1.5 \mu$ s. These estimated values are in reasonable agreement with the experimental results on the combustion wave structure that are considered above. Thus, we suggest that time in the preheating zone of the reactive wave is too short for solid-state reactions to generate significant intermixing and heat release. However, solid-state processes are known to play important roles when the RMNFs are heated slowly to the point self-ignition [51]. This phenomenon requires deeper investigation.

\section{Conclusions}

Analysis of the experimental results and molecular dynamic simulations of combustion behavior and structural evolution in the combustion wave allow us to make the following conclusions.

1) The gasless combustion wave in the reactive multilayer nanofoil Ni/Al likely consists of two stages, and the first stage can propagate independent of the second stage.

2) The velocity of propagation in the first stage is the same as the velocity of propagation in the complete wave; the steady-state value of the velocity does not depend on the method of ignition. 
3) Based on the quenching experiments the products of the first stage of combustion are likely nano-grains of $\mathrm{NiAl}$, separated by a liquid phase from the Al-Ni melt.

4) A mechanism of mosaic dissolution-precipitation is suggested for the first stage of the $\mathrm{Ni}-\mathrm{Al}$ formation reaction, which explains the experimental observations, the resulting microstructure, and the MD simulations.

5) Post-combustion processes, that likely take place behind the combustion front, involve $\mathrm{NiAl}$ grain growth and interaction between the $\mathrm{NiAl}$ grains and the residual $\mathrm{Ni}-\mathrm{Al}$ liquid. These processes can generate some heat and may delay cooling of the foil.

6) The combustion wave in the Ni/Al RMNFs is proposed to be a sequential, two stage process involving chemical (first stage) and physical (second stage) exothermic transformations.

7) While one must be cautious to extrapolate results from a given isothermal MD simulation to a self-propagating reaction that encompasses a broad range of temperatures, such simulations do provide valuable insight into possible mechanisms of mixing and phase formation.

\section{Acknowledgments}

This work is supported by the RFBR Grant 13-03-01043; it was carried out also with financial support from the Ministry of Education and Science of the Russian Federation in the framework of Increase Competitiveness Program of NUST «MISiS» (no. K2-2014-001). TPW and MDG were supported by National Science Foundation (NSF) Grant DMR-1308966. This work was also partially supported by the Department of Energy, National Nuclear Security Administration, under Award Number DE-NA0002377. We thank Mr. J. Pauls for the interest for the work and fruitful discussion, and Dr. S.A.Rogachev for computer treatment of video records.

\section{References.}

[1] T.W.Barbee, T.Weihs Ignitable heterogeneous stratified structure for the propagating of an internal exothermic chemical reaction along an expanding wave front and method of making same, US Patent № 5538795. Jul. 23, 1996. 
[2] T.P. Weihs Fabrication and Characterization of Reactive Multilayer Films and Foils, in Metallic Films for Electronic, Magnetic, Optical and Thermal Applications: Structure, Processing and Properties, K. Barmak and K. R. Coffey, Eds., Woodhead Publishing, Swaston, UK, Chapter 6, 160-243, 2014.

[3] A.J.Swiston, T.Hufnagel, T.P.Weihs, Joining bulk metallic glass using reactive multilayer foils, Scr. Mater.48 (2003) 1575-1580.

[4] J. Wang, E. Besnoin, S.J. Spey, A. Duckham, M.E. Reiss, O.M. Knioand T.P. Weihs, Room Temperature Soldering with Nanostructured Foils, Appl. Phys. Lett. 83 (2003) 3987-3989.

[5] B. Boettge, J. Braeuer, V. Wiemer, M. Petzold, J. Bagdahn, T. Gessner, Fabrication and characterization of reactive nanoscale multilayer systems for low-temperature bonding in microsystem technology, J. Micromech. Microeng. 20 (2010) 064018 (8pp).

[6] J. Braeuer,T. Gessner, A hermetic and room-temperature wafer bonding technique based on integrated reactive multilayer systems, J. Micromech. Microeng.24 (2014) 115002 (9pp).

[7] A.J.Gavens, D.VanHeerden, A.B.Mann, M.E.Reiss, T.P. Weihs, Effect of intermixing on self-propagating exothermic reactions in $\mathrm{Al} / \mathrm{Ni}$ nanolaminate foils, J. Appl. Phys. 87 (2000) 1255-1263.

[8] A.S. Rogachev, Exothermic reaction waves in multilayer nanofilms, Russ. Chem. Rev. 77 (2008) 21-37.

[9] A.S. Rogachev, A.S. Mukasyan, Combustion of heterogeneous nanostructural systems (Review), Comp. Expl. Shock Waves 46 (2010) 243-266.

[10] D.P. Adams, Reactive multilayers fabricated by vapor deposition: A critical review, Thin Solid Films, 576 (2015) 98-128.

[11] I.E. Gunduz, K. Fadenberger, M. Kokonou, C. Rebholz, C.C. Dourmanidis, Investigations on the self propagating reactions of nickel and aluminum multilayered foils, Appl. Phys. Lett., 93 (2008) 134101 (3 pp).

[12] A.S.Rogachev, S.G.Vadchenko, A.S.Mukasyan, Self-sustained Waves of Exothermic Dissolution in Reactive Multilayer Nano-Foils. Appl. Phys. Lett., 101 (2012) 063119 (4 pp).

[13] I.E. Gunduz, S. Onel, C.C. Dourmanidis, C. Rebholz, S.F.Son, Simulation of nanoscale $\mathrm{Ni} / \mathrm{Al}$ multilayer foils with intermediate $\mathrm{Ni}_{2} \mathrm{Al}_{3}$ growth, J. Appl. Phys. 117 (2015) 214904 (6 pp). [14] J.Kim, T.LaGrande, B.Reed, M.Taheri, M.Armstrong, W.King, N.Browning, G.Campbell, Imaging of transient structures using nanosecond in situ TEM, Science, 321 (2008) 1472-1475. [15] J.Kim, T.LaGrande, B.Reed, R.Knepper, T.Weihs, N.Browning, G.Campbell Direct characterization of phase transformations and morphologies in moving reaction zones in $\mathrm{Al} / \mathrm{Ni}$ nanolaminates using dynamic transition electron microscopy, Acta Mater., 59 (2011) 3571-3580. 
[16] A.S.Rogachev, J.-C.Gachon, H.E.Grigoryan, E.Illeková, N.F.Kochetov, F.N.Nosyrev, N.V.Sachkova, J.C.Schuster, M.R.Sharafutdinov, N.F.Shkodich, B.P.Tolochko, P.A.Tsygankov, I.Y.Yagubova Diffraction of synchrotron radiation for in situ study of the heterogeneous reactions mechanisms in lamellar composites, obtained by mechanical activation and magnetron sputtering. Nuclear Instruments and Methods in Physics Research A, 575 (2007) 126-129.

[17] J.C.Trenkle, L.J.Koerner, M.W.Tate, S.M.Gruner, T.P.Weihs, T.C.Hufnagel, Phase transformations during rapid heating of Ni/Al multilayer foils, Appl. Phys. Lett., 93 (2008) 081903.

[18] K. Fadenberger, I.E. Gunduz, C. Tsotsos, M. Kokonou, S.Gravani, S. Brandsteller, A. Bergamaschi, B.Schmitt, P.H. Mayrhofer, C.C. Doumanidis, C. Rebholtz, In situ observations of rapid reactions in nanoscale $\mathrm{Ni}-\mathrm{Al}$ multilayer foils using synchrotron radiation, Appl. Phys. Lett., 97 (2010) 144101 (3 pp).

[19] A.B.Mann, A.J.Gavens, M.E.Reiss, D.VanHeerden, G.Bao, T.P.Weihs. Modeling and characterizing the propagation velocity of exothermic reactions in multilayer foils, J. Appl. Phys., 82 (1997) 1178-1188.

[20] M. Salloum, O.M. Knio, Simulation of reactive nanolaminates using reduced models: I. Basic formulation, Comb. and Flame, 157 (2010) 288-295.

[21] M. Salloum, O.M. Knio, Simulation of reactive nanolaminates using reduced models: II. Normal propagation, Comb.and Flame, 157 (2010) 436-445.

[22] M. Salloum, O.M. Knio, Simulation of reactive nanolaminates using reduced models: III. Ingredients for a general multidimensional formulation, Comb. and Flame, 157 (2010) 11541166.

[23] L.Alawieh, T.P. Weihs, O.M. Knio, A generalized reduced model of uniform and selfpropagating reactionsin reactive nanolaminates, Comb. and Flame, 160 (2013) 1857-1869.

[24] A.S.Shteinberg, V.A.Shcherbakov, Z.A.Munir, Kinetics of combustion in the layered Ni-Al system, Combust. Sci. Technol.,169 (2001) 1-24.

[25] O. Politano, F. Baras, A. Mukasyan, S.G.Vadchenko, A.S. Rogachev, Microstructure development during $\mathrm{NiAl}$ intermetallic synthesis in reactive $\mathrm{Ni}-\mathrm{Al}$ nanolayers: Numerical investigations vs. TEM observations, Surface and Coatings Technology, 215 (2013) 485-492.

[26] A.S.Rogachev, S.G.Vadchenko, F.Baras, O.Politano, S.Rouvimov, N.V.Sachkova, A.S.Mukasyan, Structure evolution and reaction mechanism in the Ni/Al reactive multilayer nanofoils, Acta Mater.,66 (2014) 86-96.

[27] F. Baras and O. Politano, Molecular dynamics simulations of nanometric metallic multilayers: Reactivity of the Ni-Al system, Phys. Rev. B, 84 (2011) 024113.

[28] J.C. Crone, J. Knap, P.W. Chung, B.M. Rice, Role of microstructure in initiation of Ni-Al 
reactive multilayers, Appl. Phys. Lett. 98 (2011) 141910.

[29] R.-G. Xu, M. Falk, T.P. Weihs, Interdiffusion of Ni-Al multilayers: A continuum and molecular dynamics study, J. Appl. Phys. 114 (2013) 163511.

[30] V. Turlo, O. Politano and F. Baras, Dissolution process at solid/liquid interface in nanometric metallic multilayers: Molecular dynamics simulations versus diffusion modelling, Acta. Mater. 99 (2015) 363-372.

[31] N.S. Weingarten, W.D. Mattson, A.D. Yau, T.P. Weihs, B.M. Rice, A molecular dynamics study of the role of pressure on the response of reactive materials to thermal initiation, J. Appl. Phys. 107 (2010) 093517.

[32] S. Zhao, T.C. Germann, A. Strachan, Atomistic simulations of shock- induced alloying reactions in NiAl nanolaminates, J. Chem. Phys. 125 (2006) 164707.

[33] O. Politano, F. Baras, Molecular dynamics simulations of self-propagating reactions in NiAl multilayer nanofoils, J. Alloy Compd. 652 (2015) 25-29.

[34] M.J. Cherukara, T.P. Weihs and A. Strachan, Molecular dynamics simulations of the reaction mechanism in Ni/Al reactive intermetallics, Acta Mater. 96 (2015) 1-9.

[35] S. Plimpton, Fast parallel algorithms for short-range molecular-dynamics, J. Comp. Phys., 117 (1995) 1-19; http://lammps.sandia.gov/

[36] Y. Mishin, M. J. Mehl, D.A. Papaconstantopoulos, Embedded-atom potential for B2-NiAl, Phys. Rev. B 65 (2002) 224114.

[37] G.J. Ackland and A.P. Jones,Applications of local crystal structure measures in experiment and simulation, Phys. Rev. B, 73 (2006) 054104.

[38] M. Parrinello, A. Rahman Crystal-structure and pair potentials - a molecular-dynamics study, Physical Review Letters 45 (1980) 1196-1199.

[39] A.G.Merzhanov, B.I.Khaikin, Theory of combustion waves in homogeneous media, Prog. Energy Combust. Sci., 14 (1988) 1-98.

[40] A.Paul, A.A.Kodentsov, F.J.J. van Loo, On diffusion in the $\beta$-NiAl phase, J. Alloys and Compounds, 403 (2005) 147-153.

[41] R.Nakamura, K.Fujita, Y.Iijima, M.Okada, Diffusion mechanisms in B2 NiAl phase studied by experiments on Kirkendall effect and interdiffusion under high pressures, Acta Mater., 51 (2003) 3861-3870.

[42] Yu.S.Naiborodenko, V.I.Itin, Gasless combustion of metal powder mixtures. I. Mechanisms and details, Combust. Explos. Shock Waves, 11 (1975) 293-300.

[43] S.K. Das, J. Horbach, Influence of chemical short-range order on atomic diffusion in Al-Ni melts, Appl. Phys. Lett., 86 (2005) 011918 (3 pp). 
[44] S. Stuber, D.H. Moritz, T. Unruh, A. Meyer, Ni self-diffusion in refractory Al-Ni melts, Phys. Rev. B, 81 (2010) 024204 (5 pp).

[45] N. Jakse, A. Pasturel, Dynamic properties and local order in liquid Al-Ni alloys, Appl. Phys. Lett., 105 (2014) 031905 (4 pp).

[46] Y.Amouyal, E.Rabkin, Y.Mishin, Correlation between grain boundary energy and geometry in Ni-rich NiAl,ActaMaterialia 53 (2005) 3795-3805.

[47] A.V. Evteev, E.V. Levchenko, I.V. Belova, and G.E. Murch, Molecular Dynamics

Simulation of Surface Segregation, Diffusion and Reaction Phenomena in Equiatomic Ni-Al

Systems.The Physics of Metals and Metallography, 113 (2012) 1202-1243.

[48] C. Michaelsen, K. Barmak, T.P. Weihs, Investigating the Thermodynamics and Kinetics of Thin Film Reactions by Differential Scanning Calorimetry, J. Phys. D.: Appl. Phys.,30 (1997), 3167-3186.

[49] T.P. Weihs, M.A. Wall, T.W. Barbee, Jr., A Low Temperature Technique for Measuring Enthalpies of Formation,J. Mater. Res, 11 (1996), 1403-1409.

[50] K.V. Manukyan, W. Tan, R.J. deBoer, E.J. Stech, A. Aprahamian, M. Wiescher, S. Rouvimov, K.R. Overdeep, C.E. Shuck, T.P. Weihs, A.S. Mukasyan Irradiation-enhanced reactivity of multilayer Al/Ni nanomaterials, ACS Appl Mater Interfaces, 7 (2015) 11272-11279. [51] G. M. Fritz, J. A. Grzyb, O. M. Knio, M. D. Grapes, T. P. Weihs Characterizing solid-state ignition of runaway chemical reactions in $\mathrm{Ni}-\mathrm{Al}$ nanoscale multilayers under uniform heating, $\mathrm{J}$. Appl. Phys., 118, (2015), 135101.

\section{Nomenclature}

$\mathrm{U}$ - linear propagation velocity of combustion;

$\mathrm{L}$ - distance along the combustion propagation direction $(\mathrm{L}=0$ indicates the position of combustion front, $\mathrm{L}<0$ corresponds to initial material, $\mathrm{L}>0$ to products);

$\mathrm{T}$ - temperature;

$\mathrm{T}$ - time;

a - thermal diffusivity;

D - mass diffusivity;

$\mathrm{D}_{\mathrm{ad}}$ - mass diffusivity at adiabatic (theoretical) temperature of combustion;

$\mathrm{D}_{\max }$ - mass diffusivity at maximal experimentally measured combustion temperature;

$\mathrm{E}$ - activation energy;

$\varepsilon$ - surface energy of NiAl phase;

$\mathrm{M}$ - molecular mass;

$\rho$ - density; 
$\mathrm{d}_{0}$ - diameter of $\mathrm{NiAl}$ grains in primary product;

$\mathrm{d}_{\mathrm{F}}$ - diameter of NiAl grains in final product.

\section{FIGURES CAPTIONS}

Figure 1. The experimental schemes: (a) free-suspended foil; (b) combustion with high heat losses.

Figure 2. Self-propagation of the reaction wave in the type II foils under different experimental schemes: free - suspended (a) and under high heat losses (b); (vacuum; recording rate $25000 \mathrm{fps}$, time interval between the shown frames $0.04 \mathrm{~ms}$; exposure time $0.02 \mathrm{~ms}$ ). The white dashed line in (b) indicates edge of the quartz disk.

Figure 3. Instantaneous velocity of the combustion front propagation measured as functions of time for different ignition methods (type I foils).

Figure 4. Simultaneous spark ignition in 2 points and collision of two combustion waves in the type I foil. Asterisks are points of ignition; small rounded bright spots are molten fragments of the foil (droplets) flying out of the ignition points.

Figure 5. Brightness (temperature) profiles of the combustion waves measured (a) using computer analysis of the high-speed video frames and (b, c) using a high-frequency photo-diode. Free-standing $40 \mu \mathrm{m}$ foils of Type I (curves 1, 5 and 6); free-standing $60 \mu \mathrm{m}$ foils of Type I (4); free-standing $8 \mu \mathrm{m}$ foil of Type II (2); $8 \mu \mathrm{m}$ foil of Type II under extreme heat losses (3). Photodiode aperture is $0.4 \mathrm{~mm}$ in diameter for tests $(4,5)$ and $0.2 \mathrm{~mm}$ for test $(6)$.Video resolution is $22-25 \mu \mathrm{m}$ per pixel.

Figure 6. Position of the combustion front for type II foils measured as a function of time from the ignition point for foils under freestanding and extreme heat loss conditions. The thin straight line shows that the combustion fronts propagate with a relatively constant velocity; deviation from the linear law takes place only during the last $1.0 \mathrm{~ms}$ before extinction.

Figure 7. Microstructure of type II foils in the as-deposited state, after burning in extreme heat loss conditions, and after burning in the freestanding conditions.

Figure 8. XRD pattern for a type II foil after burning in extreme heat loss conditions. The VAl phase is either $\mathrm{VAl}_{3}$ or $\mathrm{V}_{5} \mathrm{Al}_{8}$.

Figure 9. Quenched combustion front on the RMNF surface of a type II foil. The rectangle indicates the region that was cross-sectioned for the TEM study.

Figure 10. Cross-section bright field TEM images showing the evolution of microstructure in the preheating and combustion zones of type II foils in which reactions were quenched under extreme heat loss conditions. L indicates the distance behind the quenched combustion front. 
Figure 11. Concentration profiles along the Al-rich layer measured using EDS in STEM mode as a function of distance behind the quenched reaction front. The small circles in the TEM BF image identify the points of analyses that were located in the white phase between the product grains.

Figure 12. MDS of the reaction wave propagation (from left to right). Temperature profile and snapshot of front $(\mathrm{t}=10 \mathrm{~ns})$. Inset highlights a typical region in the front. Al atoms are blue (dark gray) and $\mathrm{Ni}$ atoms are yellow (light gray).

Figure 13. Snapshots of the atomic structure of the reacting layers are shown as a function of time following isobaric-isothermal MDS at $1000 \mathrm{~K}$. Al atoms are blue (dark gray) and Ni atoms are yellow (light gray). System sections show the formation of crystalline NiAl grains.

Displacements of $\mathrm{Al}$ and $\mathrm{Ni}$ atoms between $0.5 \mathrm{~ns}$ and $2 \mathrm{~ns}$, between $6 \mathrm{~ns}$ and $20 \mathrm{~ns}$, and between 20 and $60 \mathrm{~ns}$ are shown as straight lines. The entire system consists of $39 \mathrm{Al}$ layers and $2 \times 40 \mathrm{Ni}$ layers. This corresponds to 316,602 atoms. Only the inner layer is represented completely to improve visualization.

Figure 14. Maps of the trajectories of selected $\mathrm{Ni}$ atoms from $30 \mathrm{~ns}$ to $40 \mathrm{~ns}$ within an isobaricisothermal MDS at $1000 \mathrm{~K}$. The background of the picture shows Ni-bcc atoms at $\mathrm{t}=30 \mathrm{~ns}$ belonging to a slice ( 3 atomic planes) in the (010) direction. At $40 \mathrm{~ns}$, the selected $\mathrm{Ni}$ atoms were seen to be part of the $\mathrm{NiAl}$ grains.

Figure 15. Fraction of the interface surface covered by crystalline NiAl phase and snapshots of the atomic plane parallel to the layers and close to the interface (view from the top) as a function of time.

Figure 16. Schematic diagrams showing the proposed heterogeneous reaction mechanisms: (a) reactive diffusion through a continuous solid product; (b) reactive dissolution into a liquid $\mathrm{Al}(\mathrm{Ni})$ solution; (c) a "mosaic" of reactive dissolution-precipitation. 

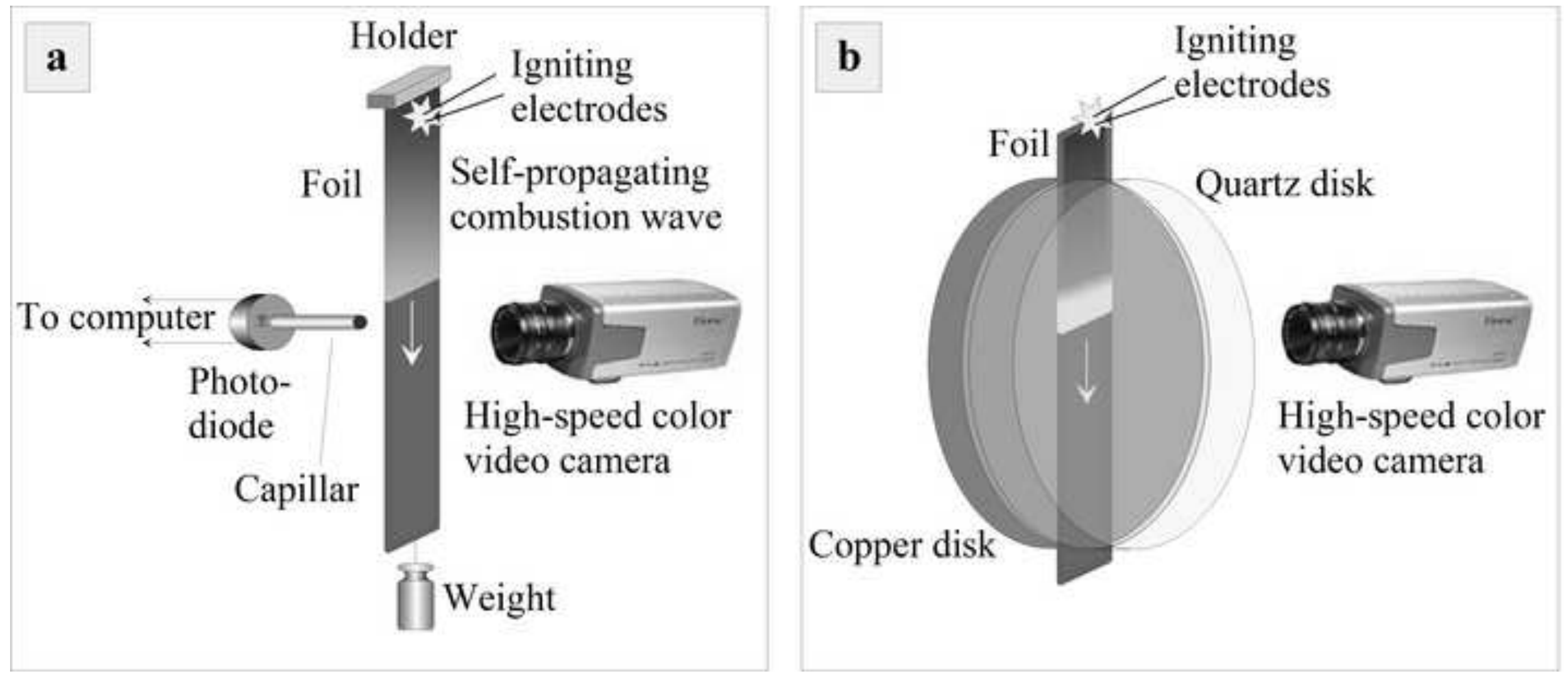

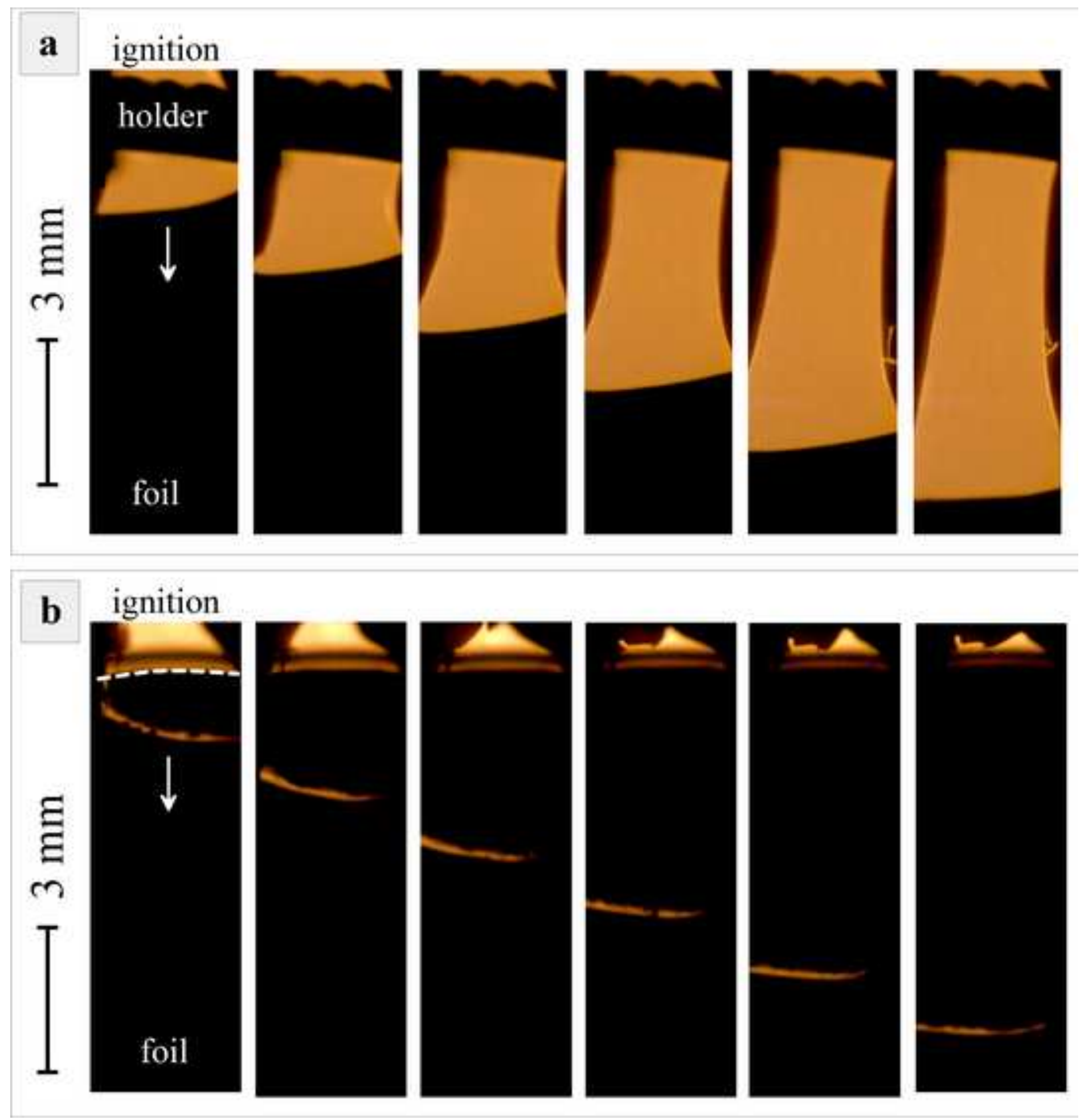


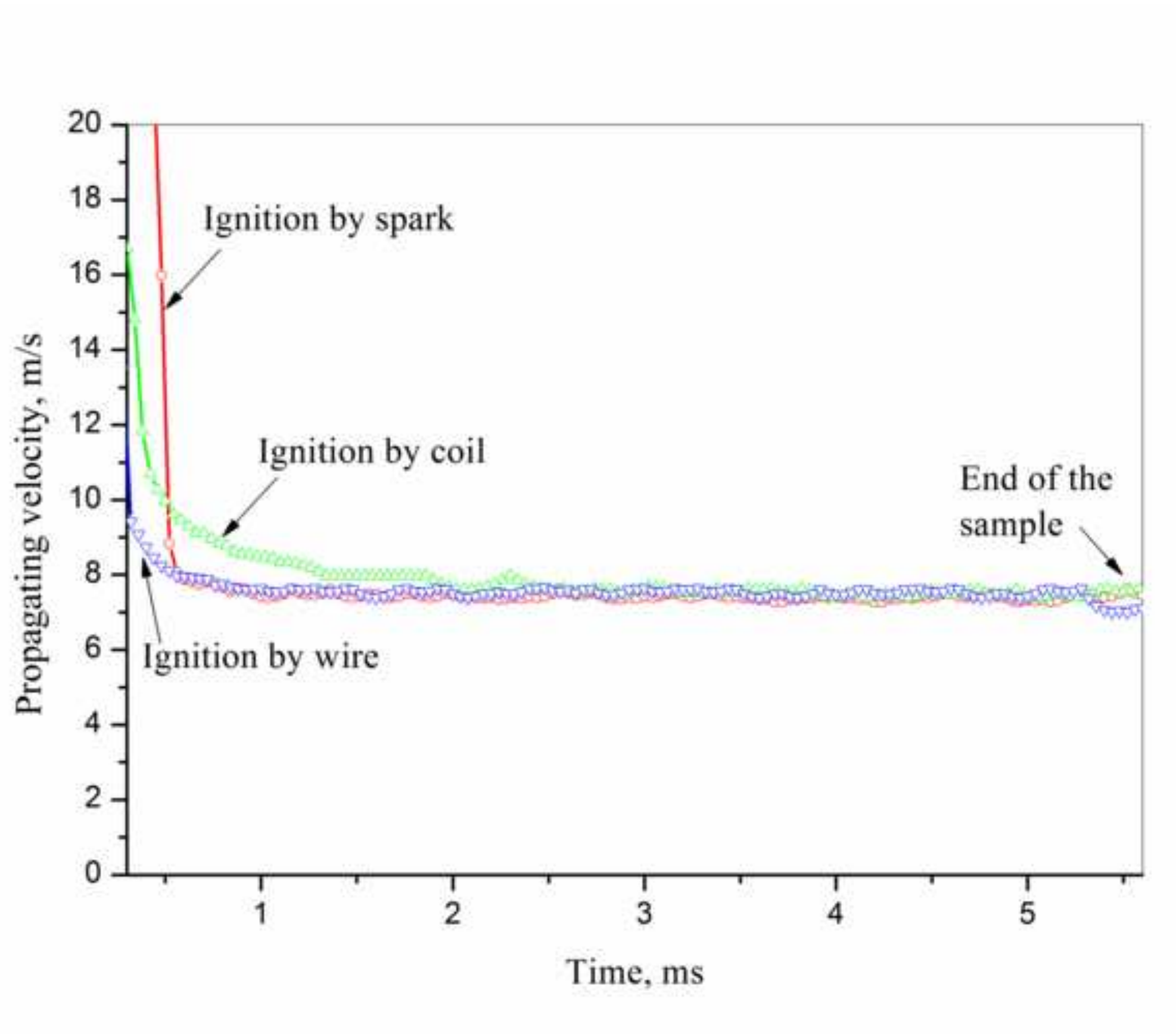

Time, ms

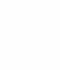

(

.

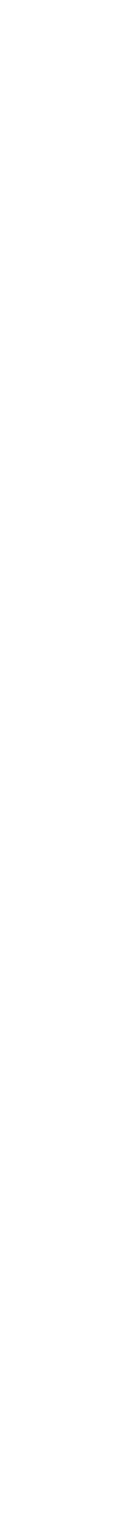

-



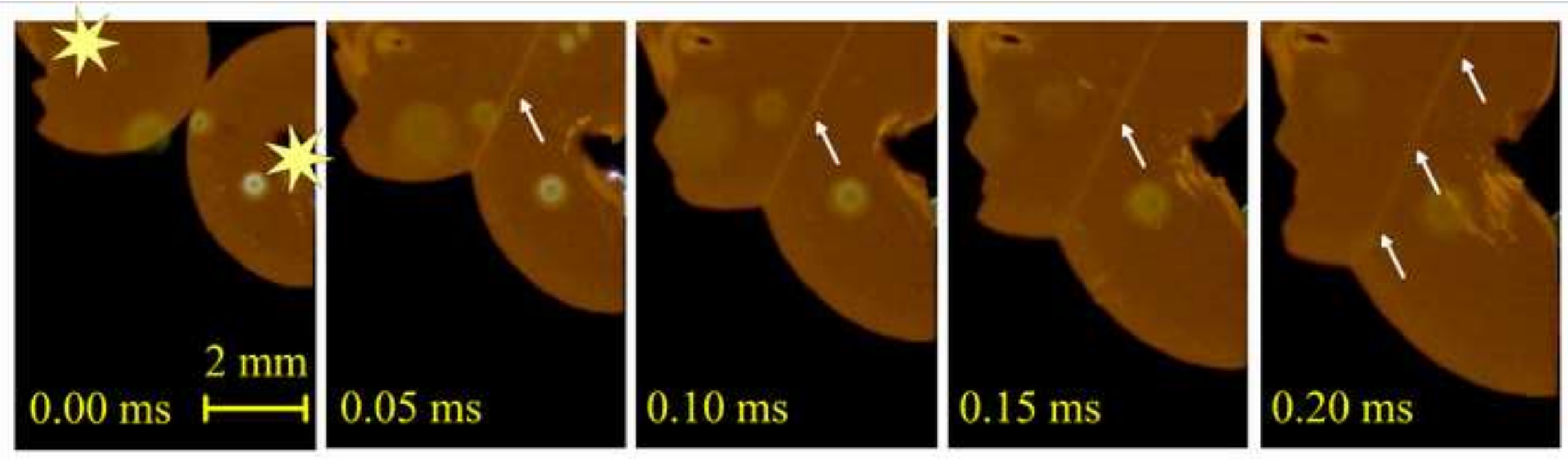

$0.15 \mathrm{~ms}$

$0.20 \mathrm{~ms}$ 


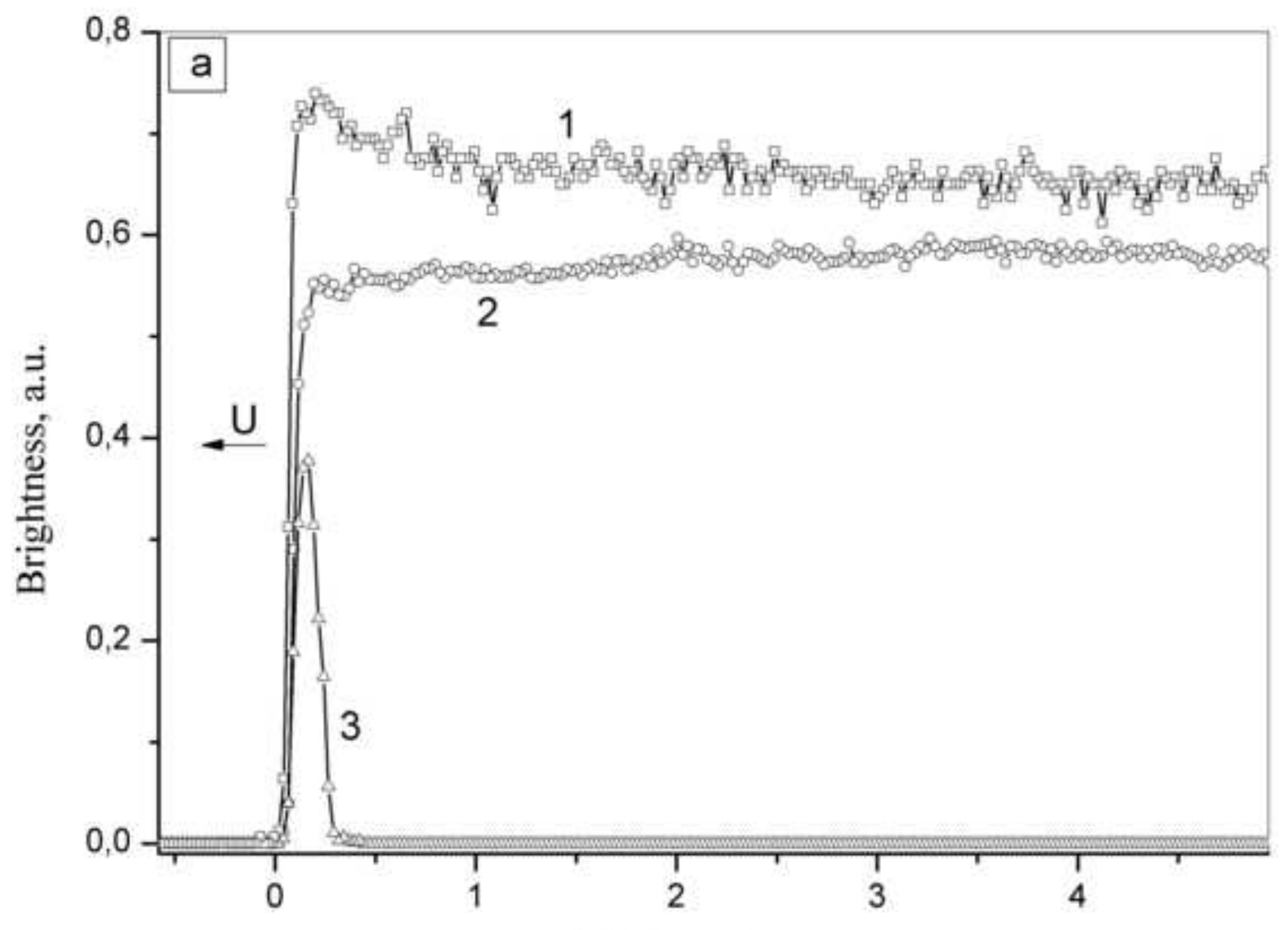

Distance L, mm 


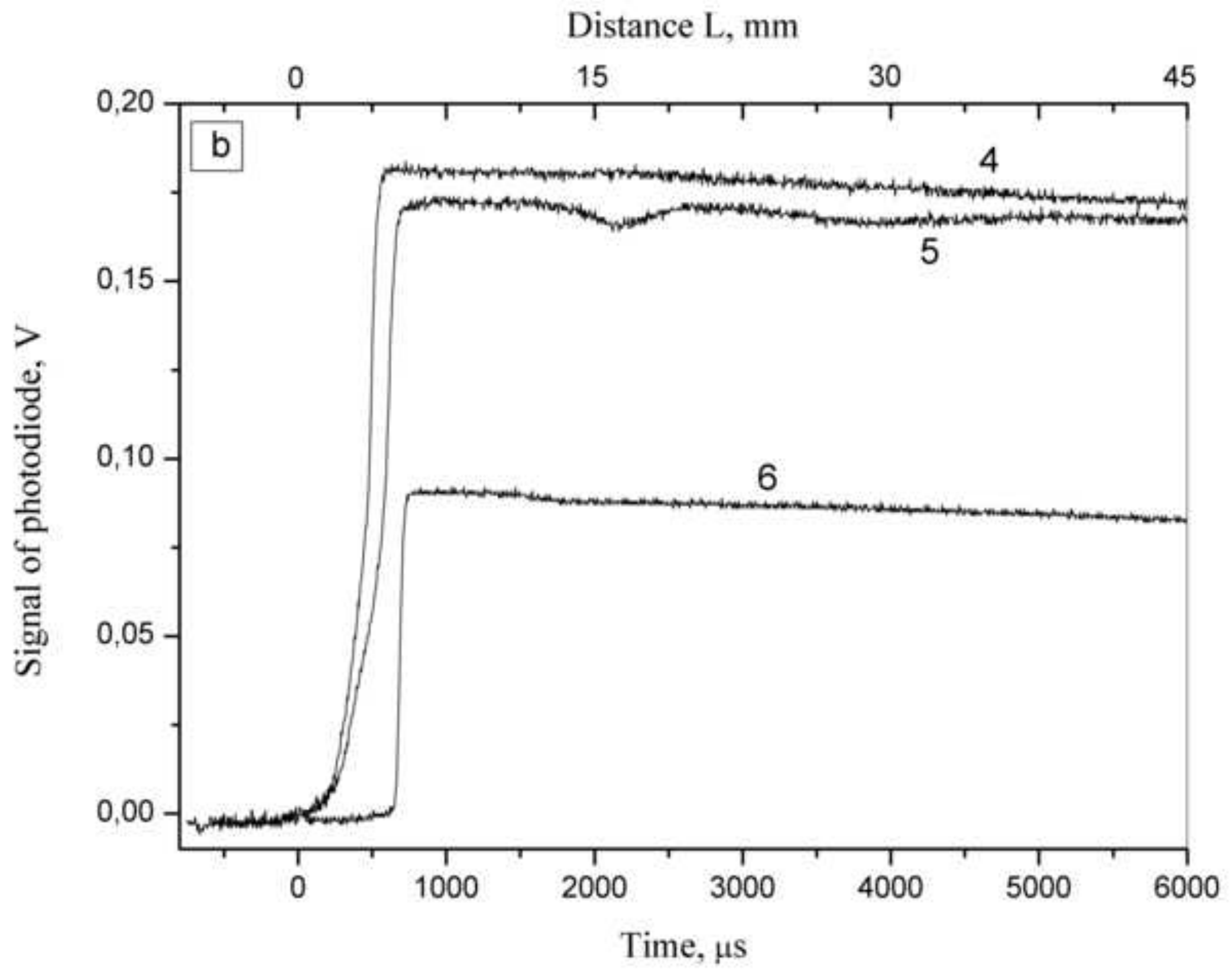




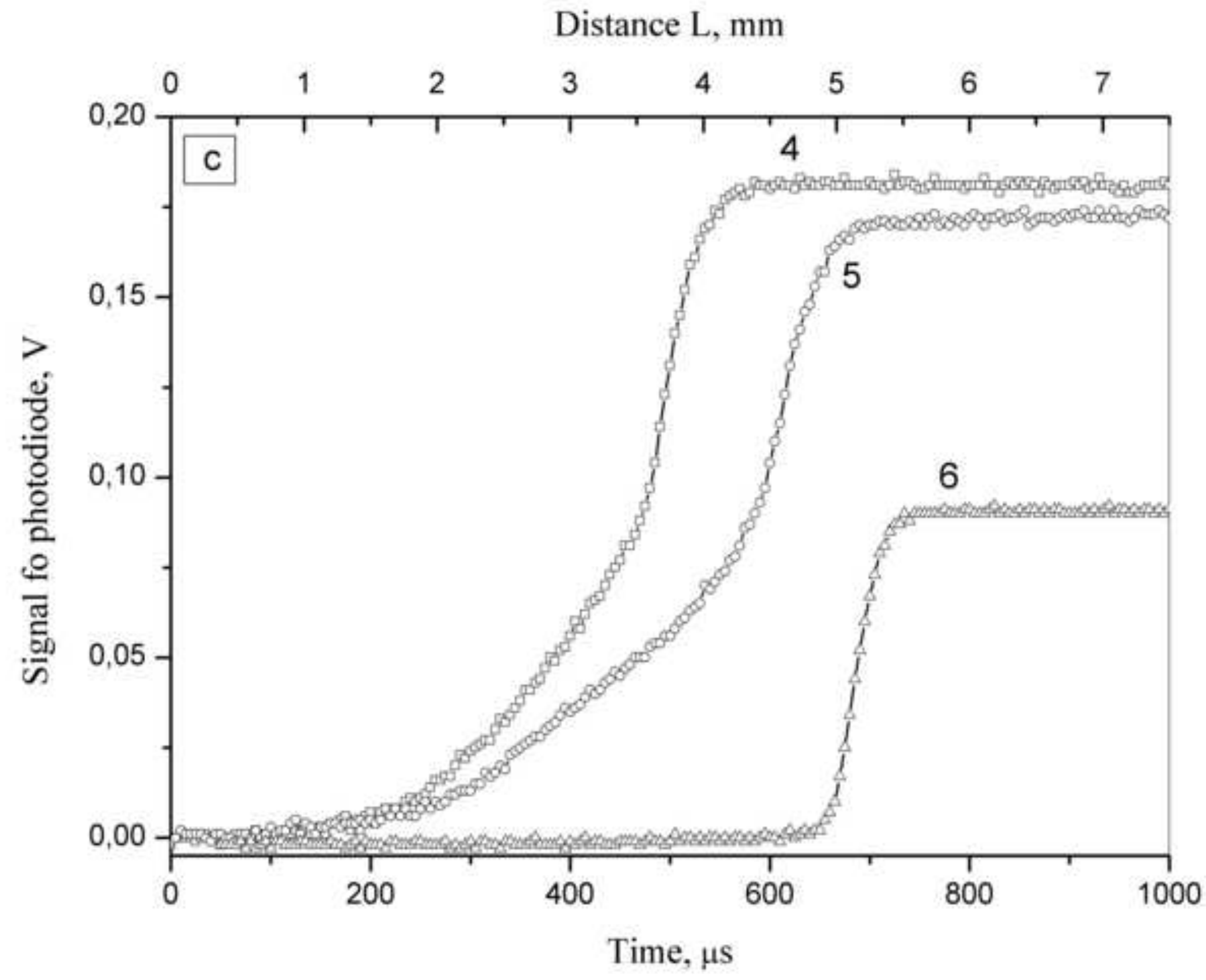




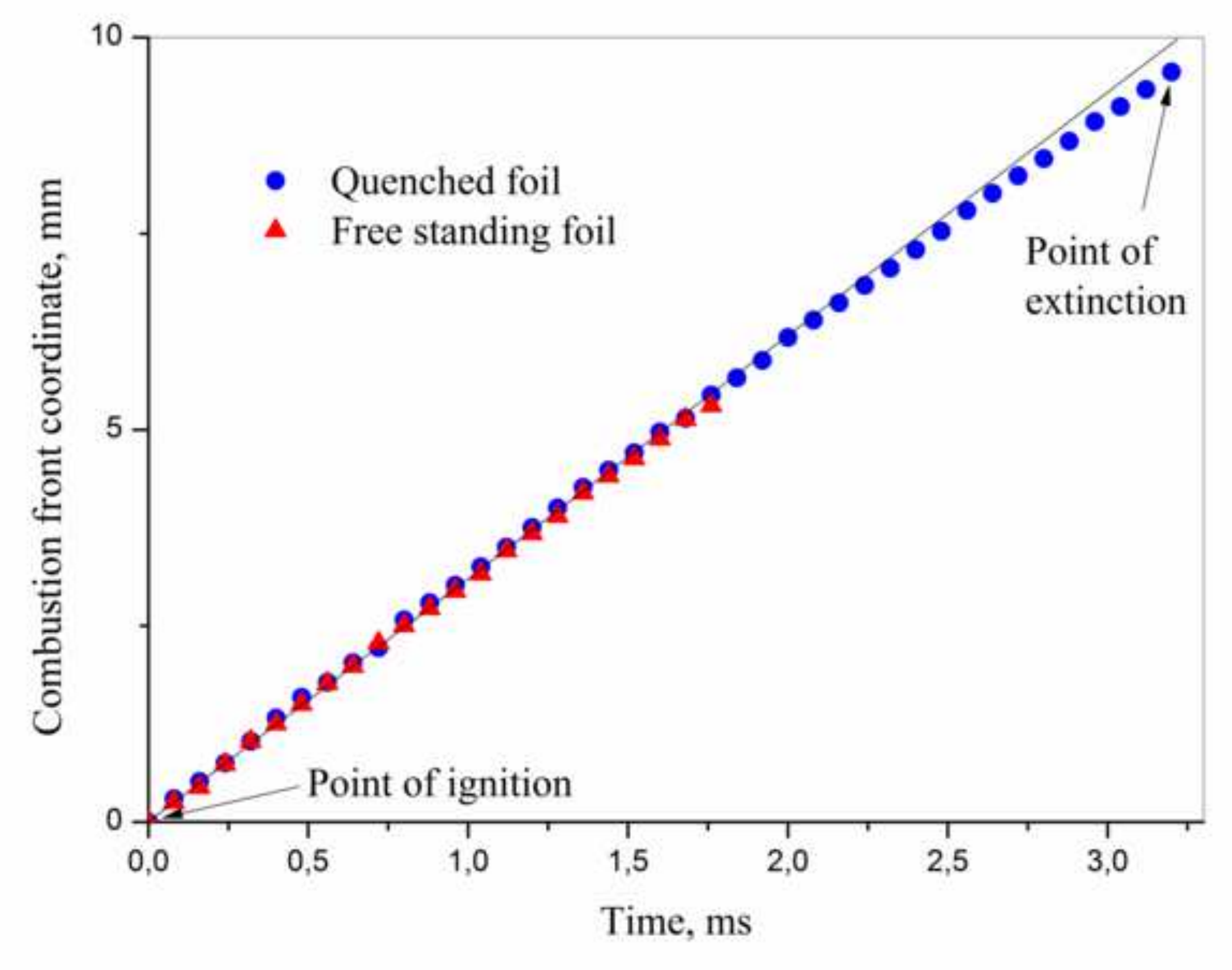

Time, ms

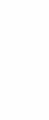

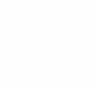

(2)

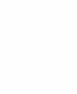




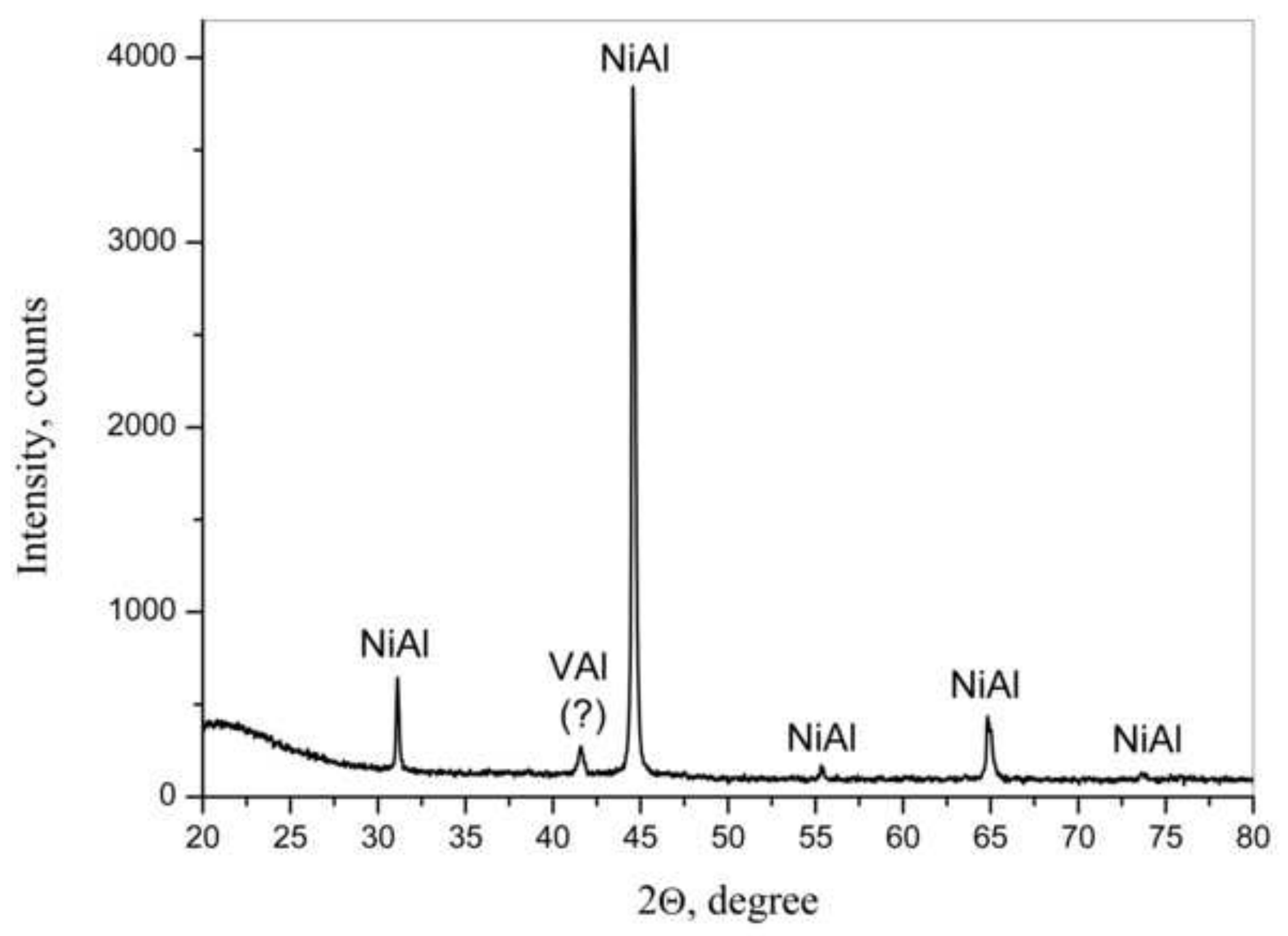



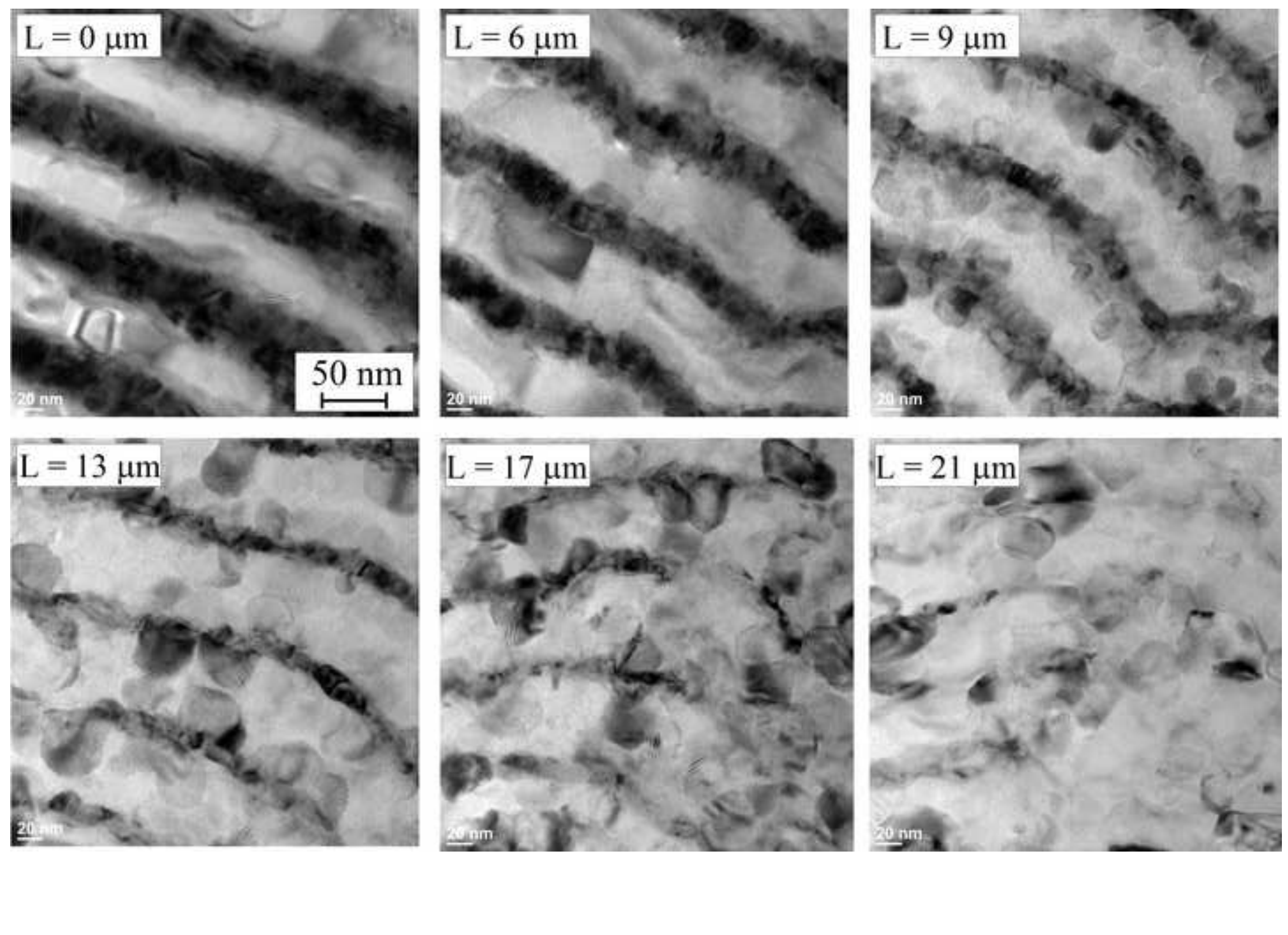


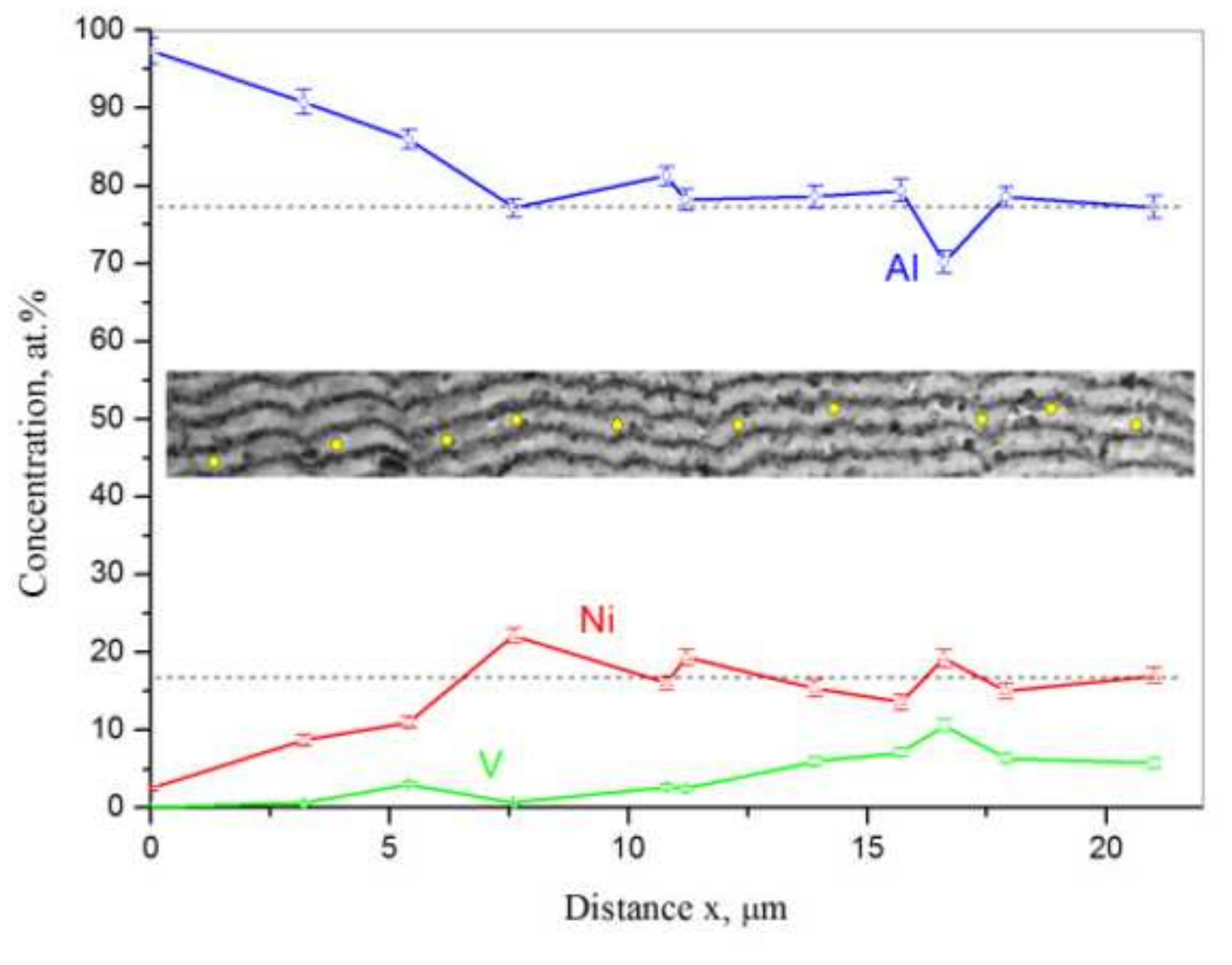

Distance $\mathrm{x}, \mu \mathrm{m}$

\section{(1)}

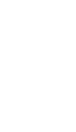

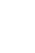
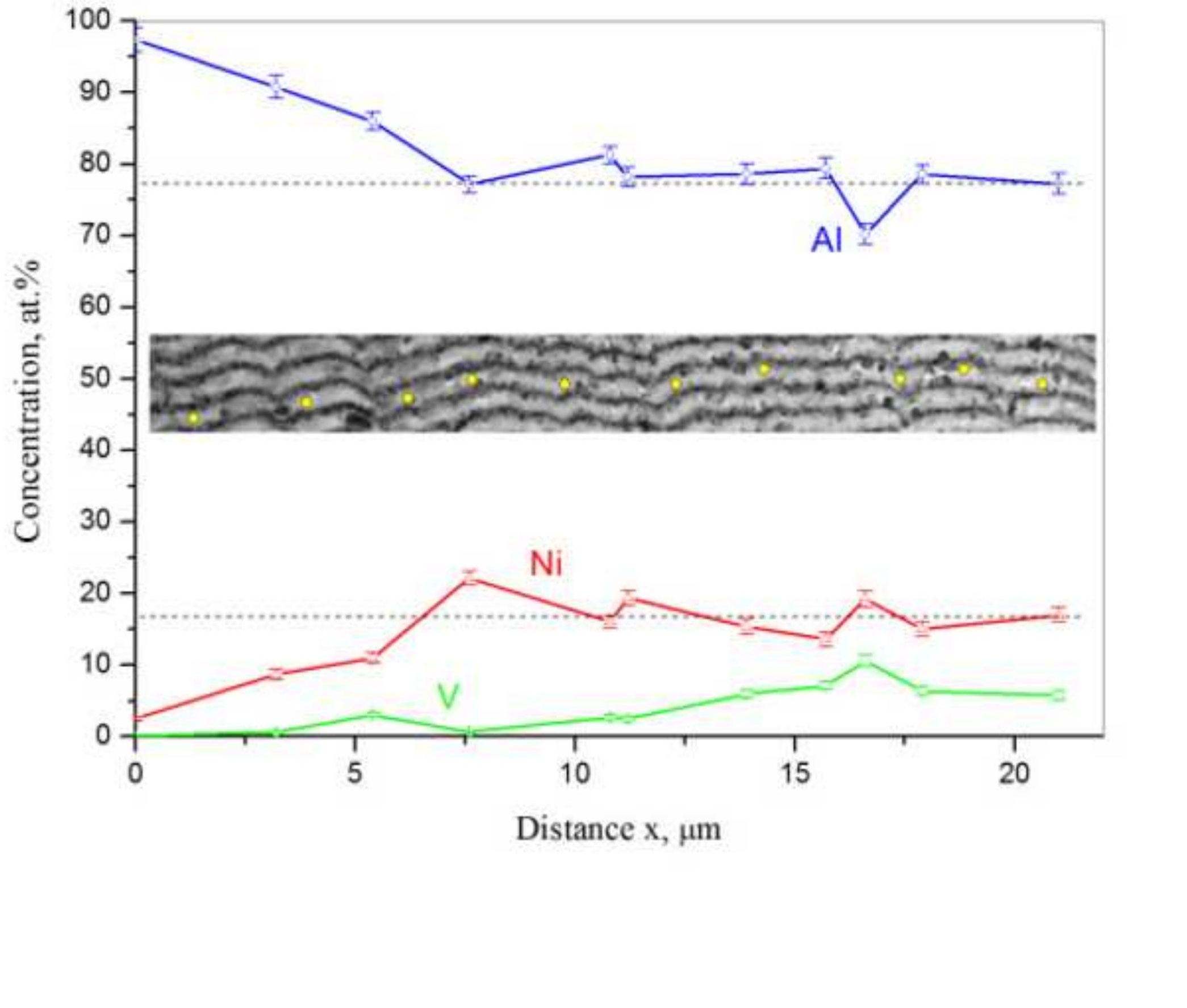

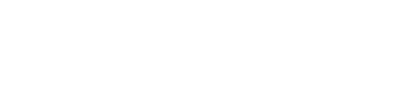




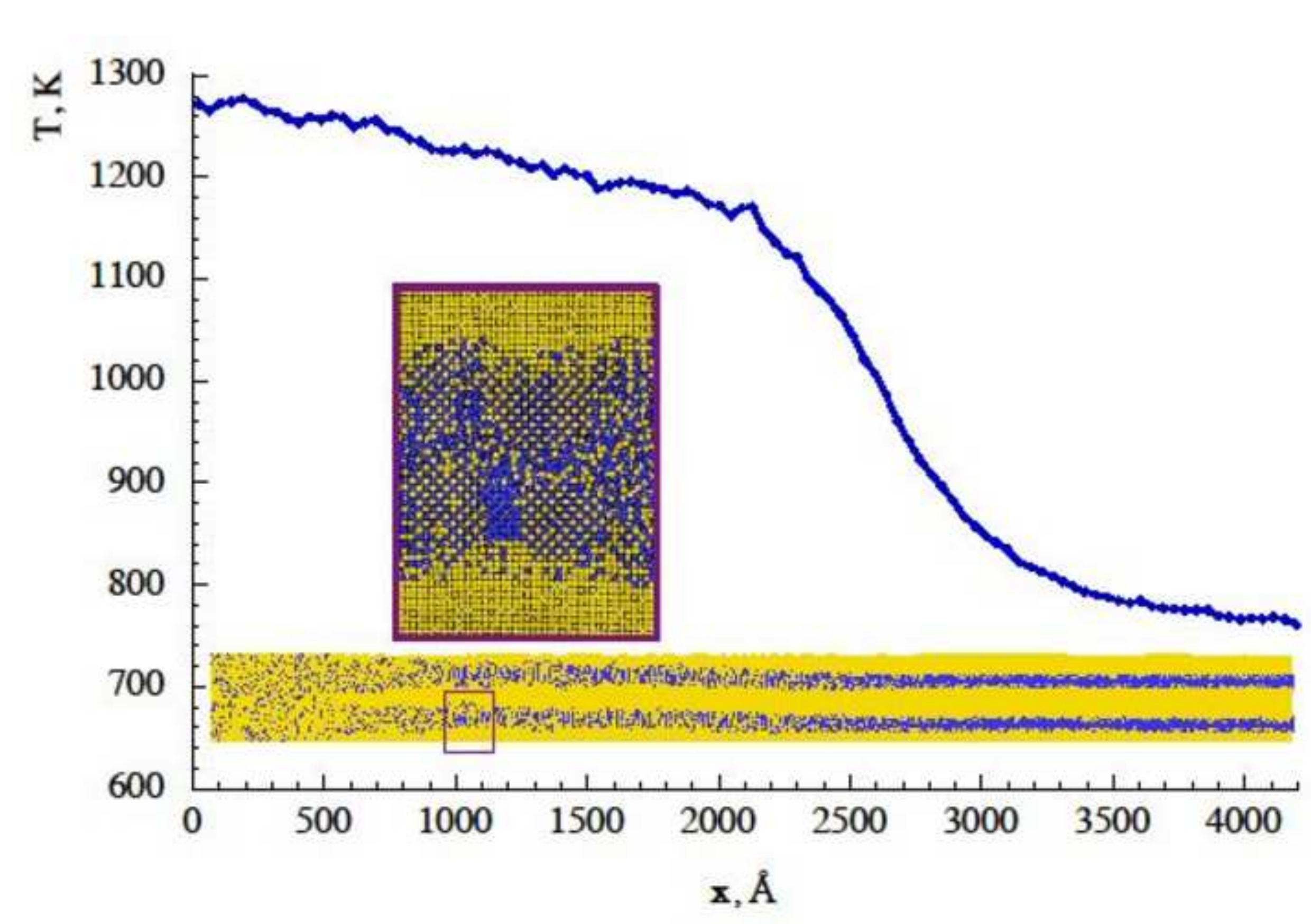

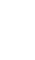

.
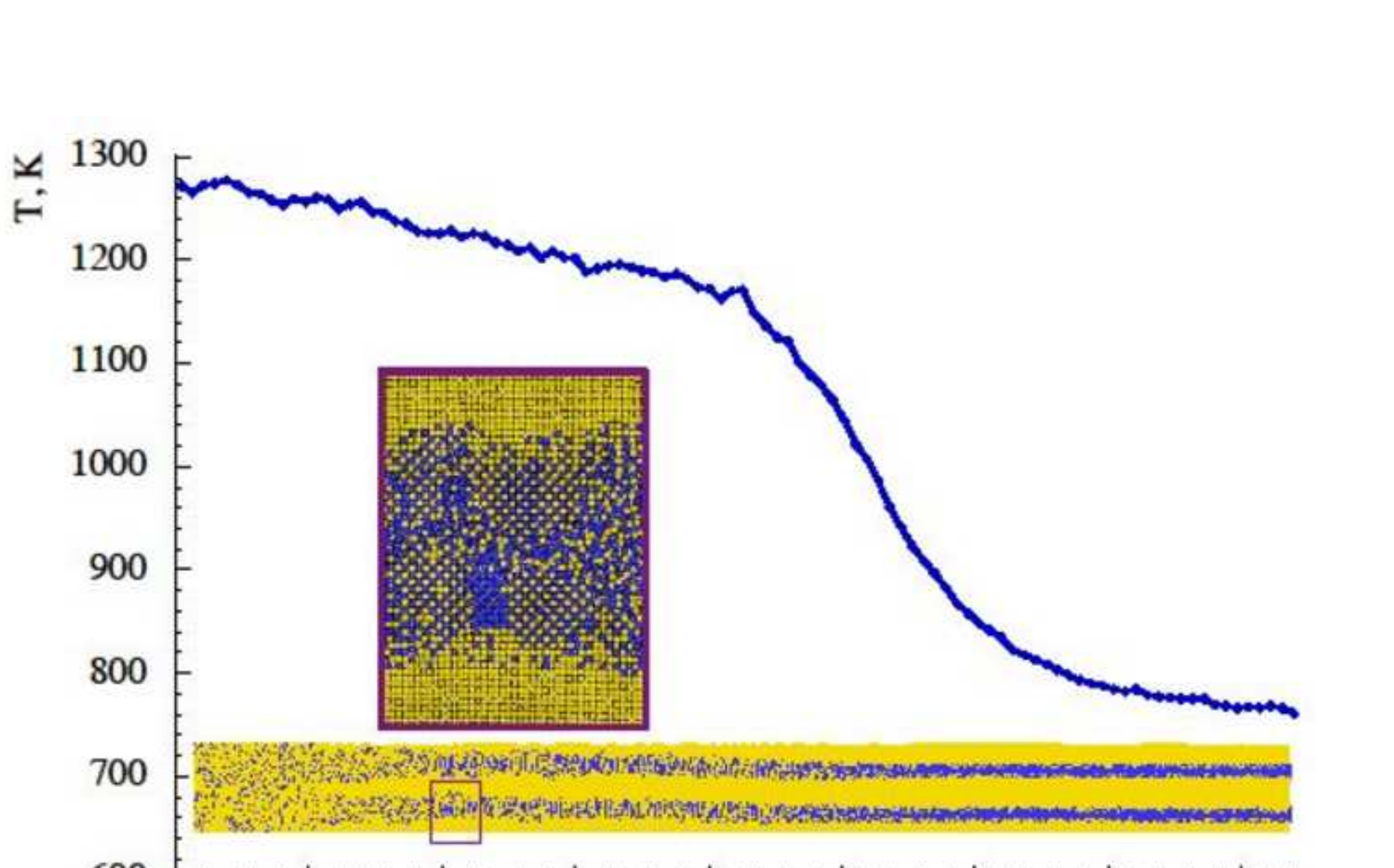

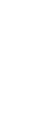
. (

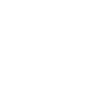
( 


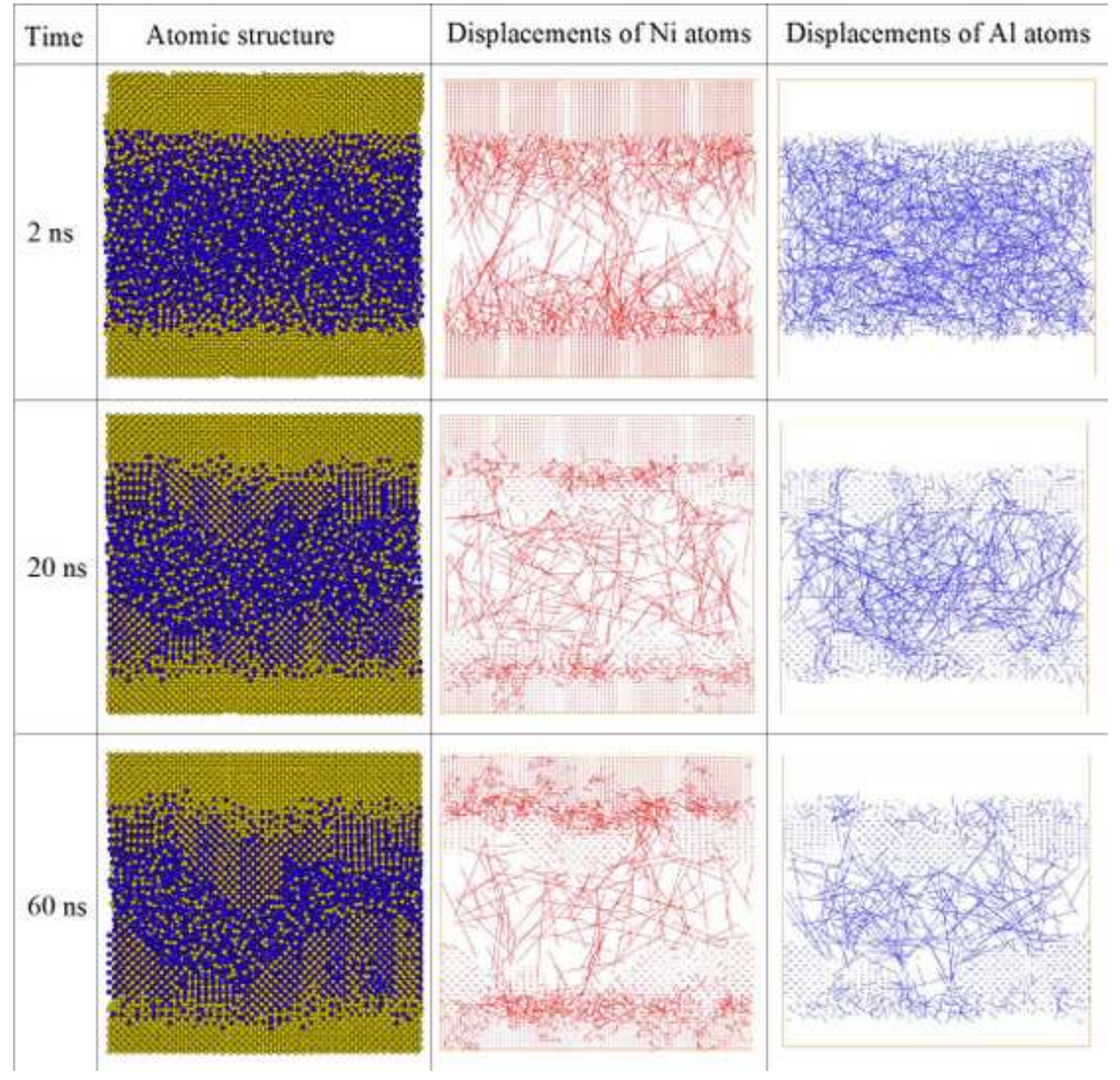

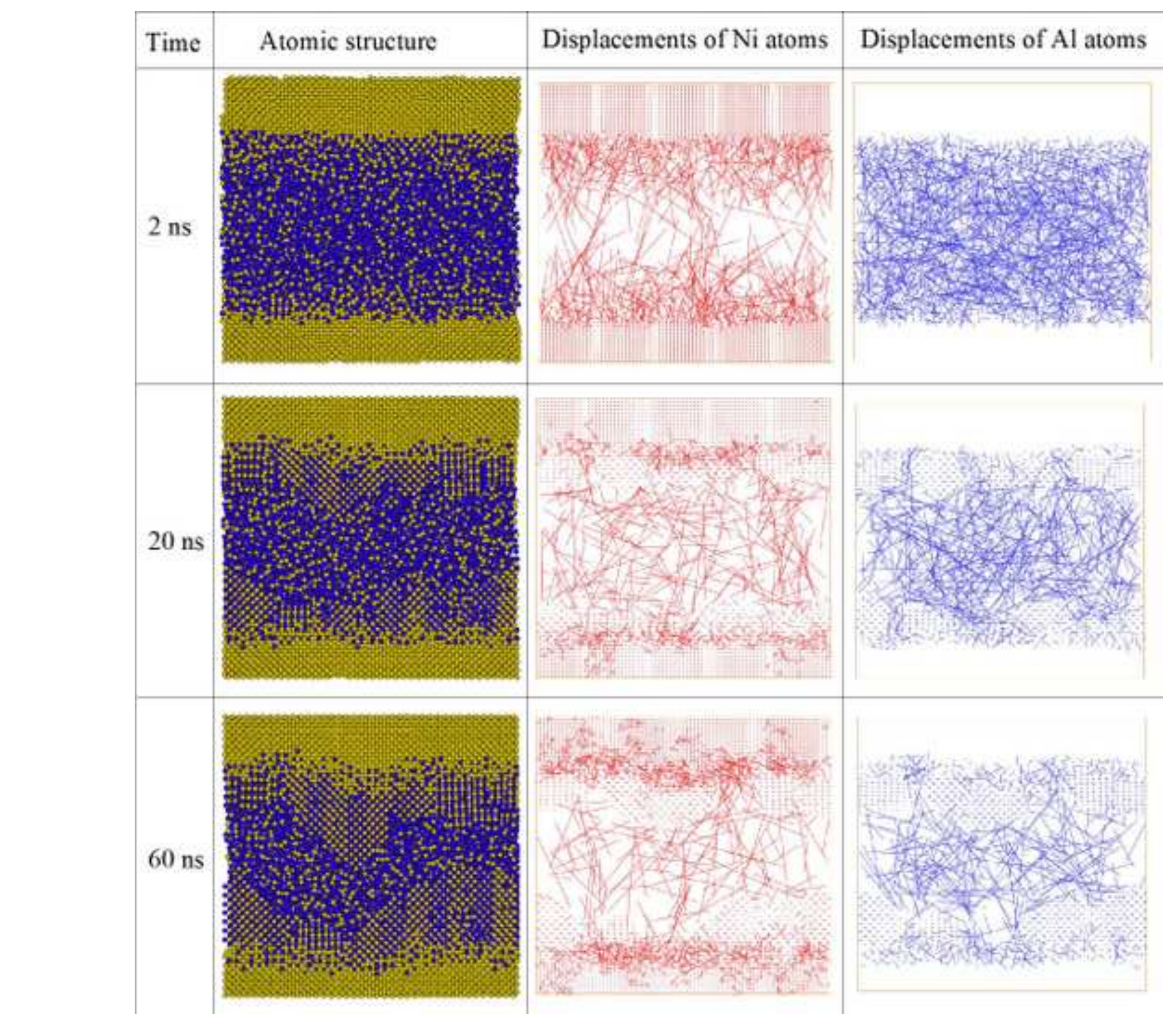




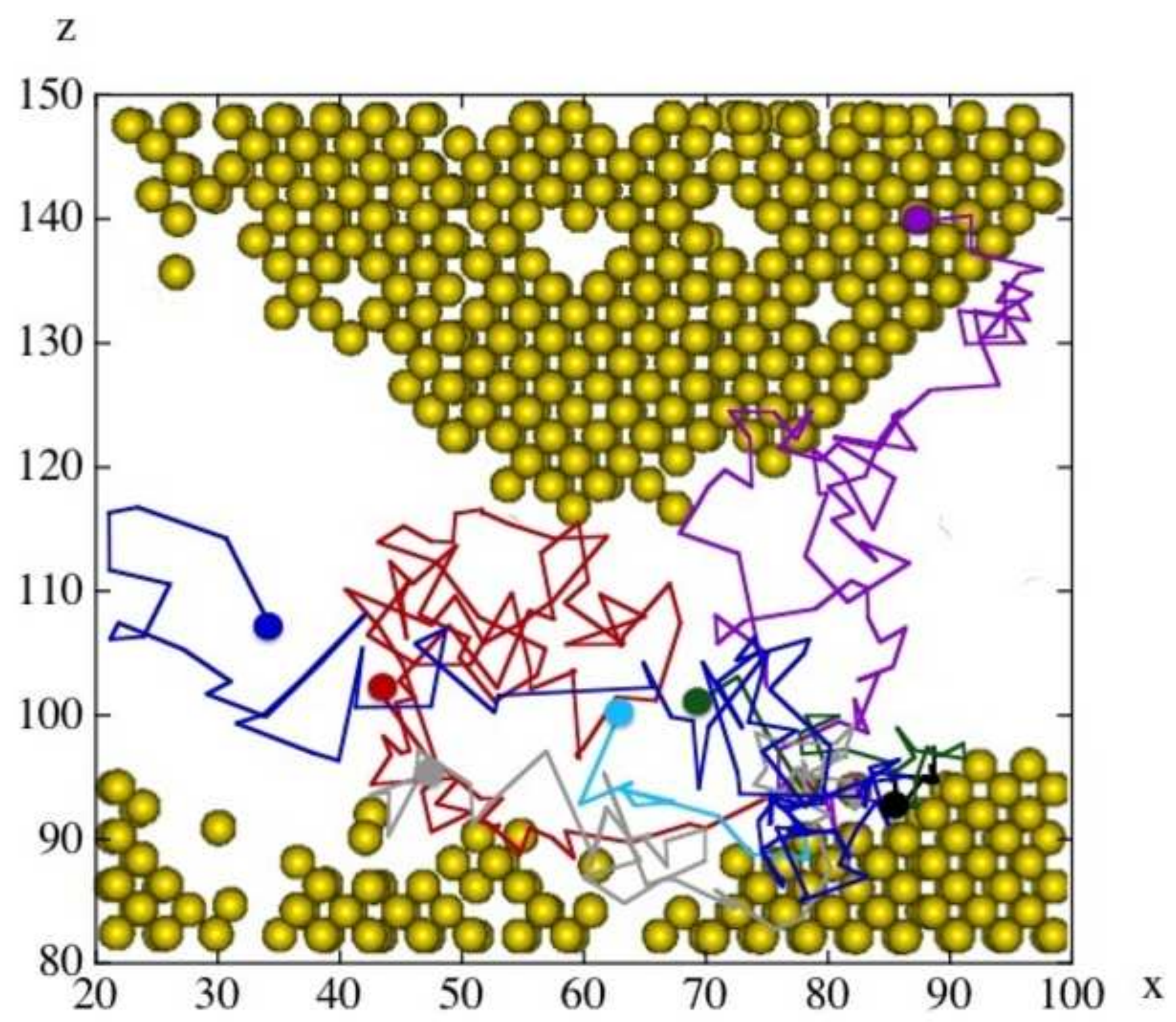




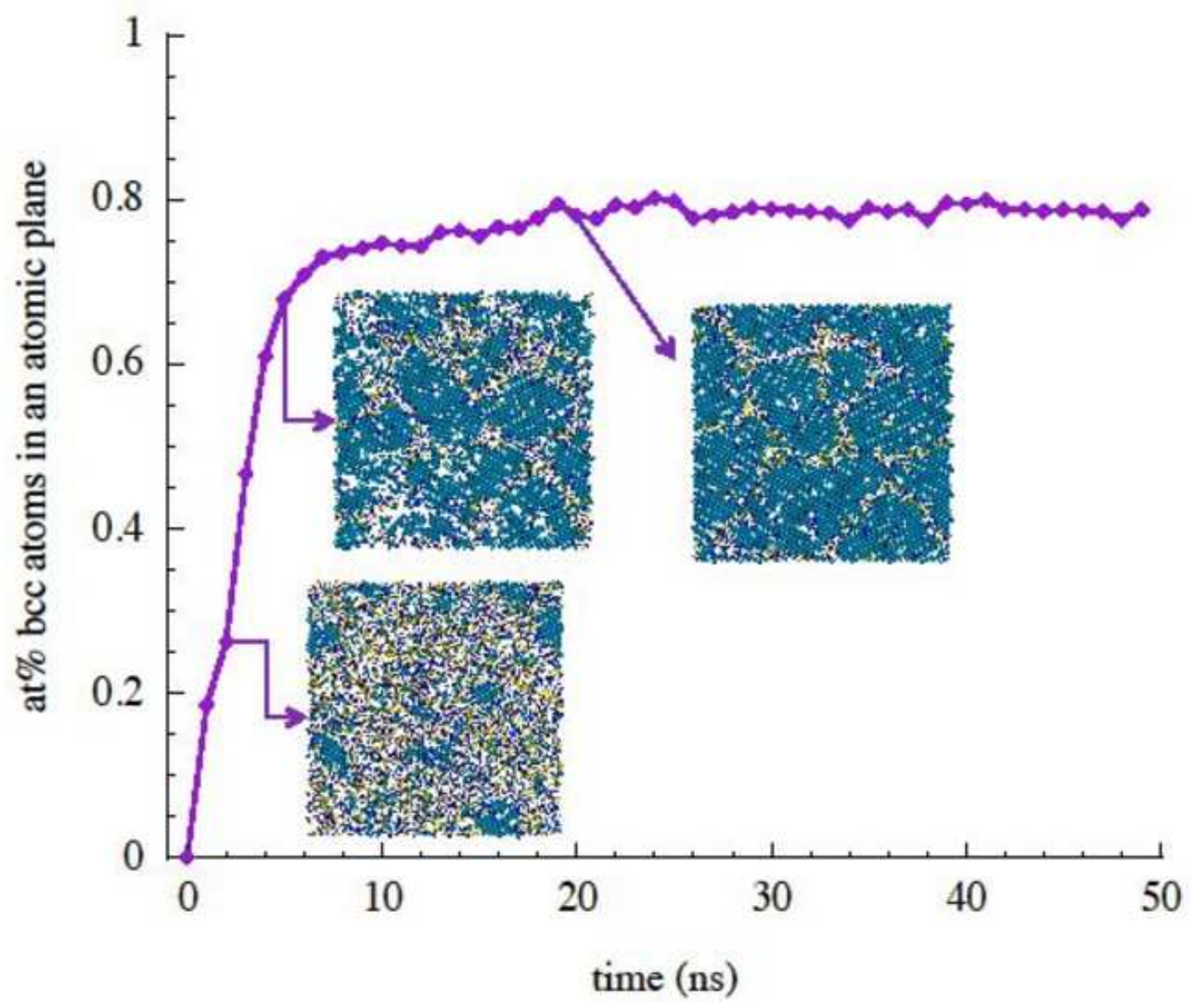



solid $\mathrm{Ni} \rightarrow$

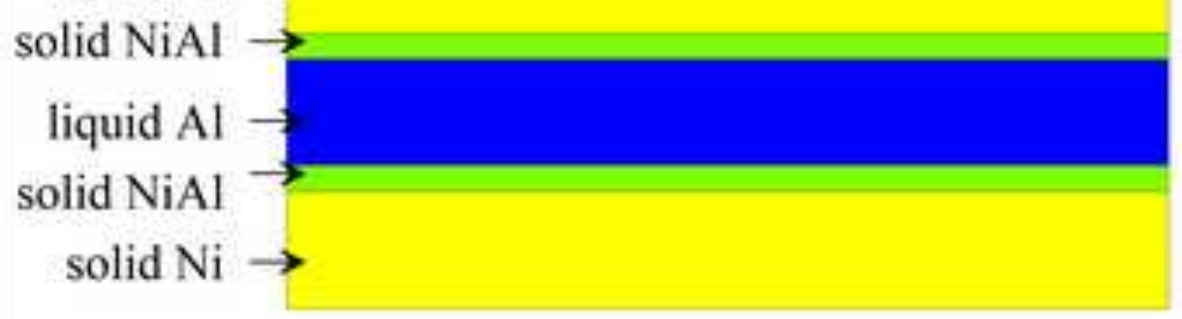

\section{a}

b

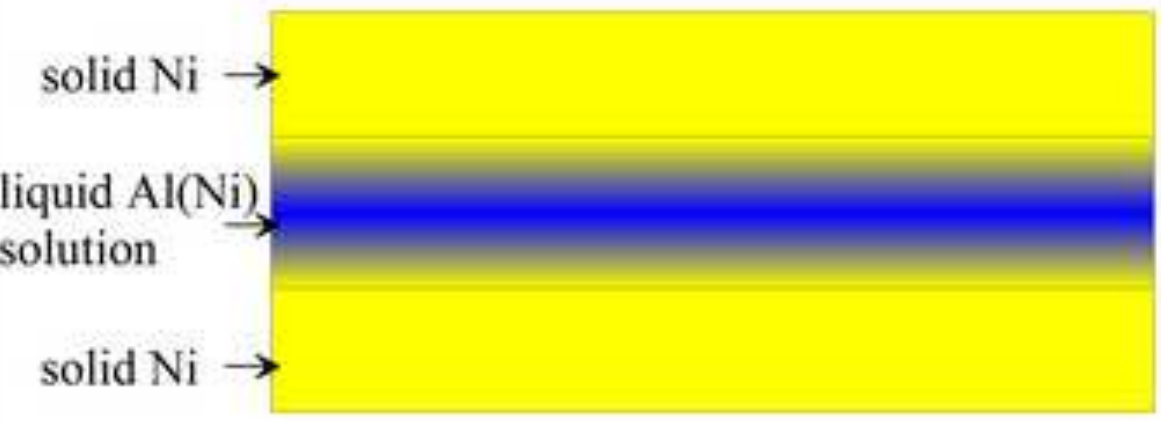

\section{c}

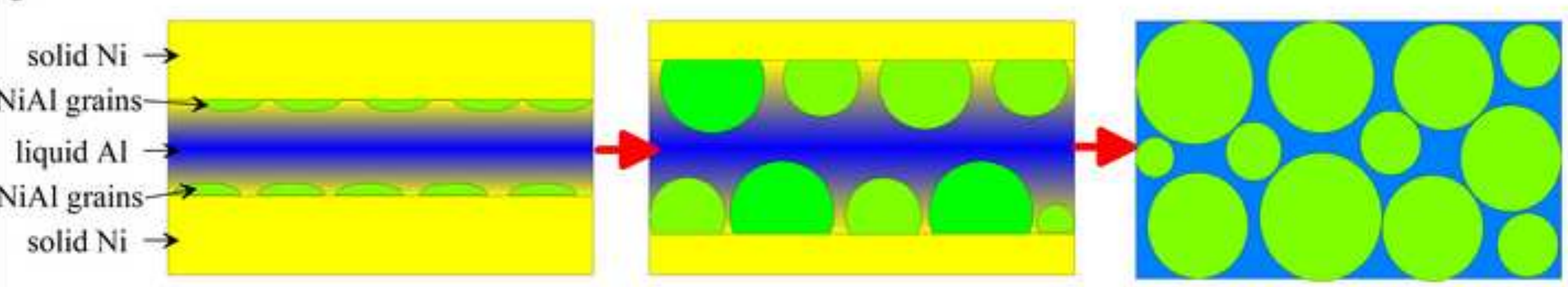

